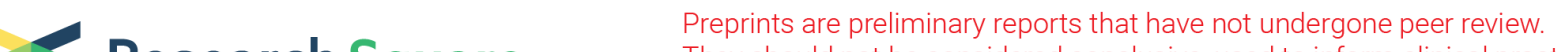 Research Square They should not be considered conclusive, used to inform clinical practice, or referenced by the media as validated information.
}

\section{Greater Morphological and Primary Metabolic Adaptations in Roots Contribute to Phosphate- Deficiency Tolerance in the Bread Wheat Cultivar Kenong199}

\section{Lu Zheng}

State Key Laboratory of Soil and Sustainable Agriculture, Institute of Soil Science, Chinese Academy of Sciences

\section{Mohammad Rezaul Karim}

State Key Laboratory of Soil and Sustainable Agriculture, Institute of Soil Science, Chinese Academy of Sciences

\section{Yin-Gang Hu}

State Key Laboratory of Crop Stress Biology for Arid Areas, College of Agronomy, Northwest A\&F University

\section{Renfang Shen}

State Key Laboratory of Soil and Sustainable Agriculture, Institute of Soil Science, Chinese Academy of Sciences

\section{Ping Lan ( $\sim$ plan@issas.ac.cn )}

State Key Laboratory of Soil and Sustainable Agriculture, Institute of Soil Science, Chinese Academy of Sciences

\section{Research Article}

Keywords: Phosphate deficiency, Wheat, Roots, Signaling, Metabolites

Posted Date: April 22nd, 2021

DOl: https://doi.org/10.21203/rs.3.rs-429086/v1

License: (1) (i) This work is licensed under a Creative Commons Attribution 4.0 International License. Read Full License

Version of Record: A version of this preprint was published at BMC Plant Biology on August 19th, 2021. See the published version at https://doi.org/10.1186/s12870-021-03164-6. 


\section{Abstract \\ Background}

Phosphate $(\mathrm{Pi})$ deficiency severely affects crop growth and productivity, including wheat, therefore it is necessary to develop cultivars with enhanced Pi-deficiency tolerance. However, the underlying mechanism of Pi-deficiency tolerance in wheat is still elusive. Two contrasting wheat cultivars, low-Pi tolerant Kenong199 (KN199) and low-Pi sensitive Chinese Spring (CS) were used to reveal adaptations in response to Pi deficiency at the morphological, physiological, metabolic, and molecular levels.

\section{Results}

KN199 was more tolerant to Pi deficiency than CS with significantly increased root biomass and R/S ratio. Root traits, the total root length, total surface area, and total volume, were remarkably enhanced by Pi deficiency in KN199. The shoot soluble Pi and total P concentrations of KN199 were all significantly higher than these of CS, but not in roots. In KN199, high Pi level in shoots is a higher priority than that in roots under Pi deficiency. It was probably due to differentially regulation in the miR399-mediated signaling network between the shoots of the two cultivars. The Pi deficiency-induced root architecture adaptation in KN199 was attributed to the regulation of the hormone-mediated signaling (ethylene, gibberellin, and jasmonates). The expression of genes associated with root development and Pi uptake was enhanced in KN199. Some primary metabolites (amino acids and organic acids) were significantly accumulated in roots of KN199 under Pi deficiency.

\section{Conclusions}

The low-Pi tolerant wheat cultivar KN199 possessed greater morphological and primary metabolic adaptations in roots than CS under Pi deficiency. The adaption and the underlying molecular mechanism in wheat provide a better understanding of the Pi-deficiency tolerance and the strategies for improving $\mathrm{Pi}$ efficiency in wheat.

\section{Background}

Phosphorus $(P)$ is an essential macronutrient required for plant growth and development. It is one of the main constituents of nucleic acids, phospholipids, ATP and phosphorylated enzymes, and so on [1]. Phosphorus in plants is acquired from the soil mainly by uptake of inorganic phosphate ( $\mathrm{Pi})$. However, $\mathrm{P}$ exists as various insoluble phosphate minerals or organic complexes and unevenly distributed in soils [2]. Compared with other macronutrients, $\mathrm{P}$ is the most immobile, inaccessible, and unavailable one. Low $\mathrm{Pi}$ availability is often a primary limiting factor for plant growth, development, productivity, and quality in agricultural systems [3]. 
To adapt to low-Pi environments, plants have evolved several complex and elaborate responsive and adaptive mechanisms to maintain $P$ homeostasis, including root system architecture (RSA) modification, organic acid exudation, production and secretion of phosphatases, and association of the roots with soil microbes, and so on [4,5]. Meanwhile, plants modulate primary, secondary, and lipid metabolism for high Pi uptake and utilization efficiency. Among them, RSA is a crucial component for enhanced root exploration capacity and $\mathrm{Pi}$ uptake capacity due to low mobility and uneven distribution of $\mathrm{Pi}$ in soil [6]. The modification of root traits varies significantly across species and cultivars. In Arabidopsis thaliana ecotype Col-0, phosphate starvation inhibited the primary root growth, but lateral roots and root hairs increased [7]. In all 15 rice (Oryza sativa L.) genotypes tested, Pi deficiency significantly reduced large lateral root density and small and large lateral root length, increased root hair length and density [8]. However, the degree of plasticity and relative allocation of root length varied among genotypes. In wheat (Triticum aestivum), Pi deficiency changed the branching distribution of root architecture from linear (evenly spaced branches) to exponential (a greater number of branches at the top of the soil) [9]. Moreover, da Silva et al. [10] reported the Brazilian wheat cultivars with higher values of $P$ uptake exhibited total root shallow, enhancing root proliferation in P-rich surface soil.

The adaptations to Pi starvation at morphological, biochemical, and physiological levels firstly contributed to local and systemic sensing and signaling systems [11, 12]. After changes of external Pi concentration, $\mathrm{Pi}$ itself, hormones, microRNA, and sugars serve as signals to elicit transcriptional and posttranslational responses. miR399 is one of the best characterized and important MicroRNA-mediated P-signaling and well conversed in plants. The miR399 signaling pathway includes several key Pi deficiency responsive genes, phosphate starvation response 1 (PHR1) [13], induced by phosphate starvation 1 (IPS1), SPX (named after SYG1/PH081/XPR1) [14], and PHOSPHATE2 (PHO2). Besides, many hormones serve as $\mathrm{Pi}$ signaling components in developmental reprogramming, leading to changes in RSA [12], such as auxin [15], ethylene [16], gibberellin (GA) [17], and jasmonates (JAs). In Arabidopsis, local modifications of auxin concentration induced by low $\mathrm{P}$ availability involved in the lateral root development [15]; inhibition of ethylene production or action decreased root elongation under $\mathrm{Pi}$ deficiency [18]. Transcript levels of genes involved in hormone production, sensitivity, and transport were regulated under Pi stress [19]. The metabolic changes are the ultimate representation of gene expression. The metabolite profiling could provide a broader view for the final systematic adjustment [20-22]. Metabolomic analysis revealed Pi deficiency led to increases of amino acids, ammonium metabolites, and di- and tri-saccharides, decreases of small P-containing metabolites, and various changes of organic acids in the tricarboxylic acid (TCA) in barley [21], maize [22], common bean [23], and soybean [24]. These changes are the results of more efficient utilization of carbon, nitrogen, and $\mathrm{P}$ under low-Pi conditions.

Molecular mechanisms underlying Pi signaling, adaptation and metabolic changes were extensively studied in Arabidopsis and rice $[11,12,25,26]$. Wheat is one of the most economically important cereal crops in the world. The growth and yield of wheat are limited to low $P$ availability in soil [27]. Thus, $P$ fertilizers are widely and continuously supplied in agricultural production. The consumption of chemical P fertilizers in China had increased approximately 100-fold, from 0.05 Mt in 1960 to $5.3 \mathrm{Mt}$ in 2010 [28]. But, the excessive application of $\mathrm{P}$ fertilizer causes eutrophication and toxic algal blooms in aquatic 
ecosystems [29]. According to the Food and Agriculture Organization (FAO) of the United Nations (FAO Fertilizer and Plant Nutrition Bulletin 17; http://www.fao.org), approximately $46 \%$ of the P fertilizers for cereals applied to wheat and barley. So, it is of great importance to improve low-Pi tolerance in wheat for practical food security and agricultural sustainability. For the complexity of the hexaploid genome, the related studies in wheat are lagging compared with its importance in food crops.

China is the world's largest wheat producer in the last twenty years (110 million metric tonners per year from 1994-2016, data obtained from FAO). The average yield in China was steadily increasing from 3.43 t/ha in 1994 to $5.41 \mathrm{t} /$ ha in 2016. It partly contributed to the breeding and popularization of new cultivars with good qualities, stress tolerances, and high yield. Kenong199 (KN199) was one of the main cultivated wheat cultivars in the northern region of the Huang-Huai winter wheat production base for many years with high stress resistance and grain yield [30]. In field experiment, KN199 displayed high tillering capacity, spike formation, and harvest production under low P input [31]. However, its underlying mechanism of the low-Pi tolerance of KN199 was still unclear to us. In this study, we demonstrated the morphological, physiological, metabolic, and molecular characteristics of KN199 in response to Pi deficiency by comparing them with the low-Pi sensitive cultivar Chinese Spring (CS). Our results revealed that the low-Pi tolerant KN199 possessed greater morphological and primary metabolic adaptations in roots under Pi deficiency. This study provides useful information to understand the mechanisms of low-Pi tolerance in wheat.

\section{Results}

\section{KN199 was more tolerant to Pi deficiency than CS with significantly increased root biomass and R/S ratio}

To elucidate the low-Pi tolerance mechanism, the effect of Pi deficiency on the two contrasting cultivars, $\mathrm{CS}$ and KN199, was investigated at the seedling stage under hydroponic conditions. The growth of low-Pi sensitive cultivar CS was seriously inhibited after seven days of Pi deficiency treatment. Compared with sufficient $\mathrm{Pi}(+\mathrm{Pi})$ condition, the shoot fresh weight (FW) of CS was dramatically decreased by $39 \%$ under deficient $\mathrm{Pi}(-\mathrm{Pi})$ condition, while the shoot FW of low-Pi tolerant cultivar KN199 was not significantly affected (Fig. 1, a). Conversely, the root FWs of the two cultivars were both significantly increased under Pi deficiency (Fig. 1, b). Moreover, the increase of root FW in KN199 was much higher than that in CS (27 $\%$ and $58 \%$ increase in CS and KN199, respectively). Under sufficient Pi condition, the FW of KN199 was lower than that of CS, so the R/S ratio (FW) of KN199 was higher than that of CS (Fig. 1, C). The R/S ratios were significantly increased by Pi deficiency treatment in both cultivars. And the R/S ratio of KN199 under Pi deficiency reached the highest value. The root and shoot dry weight (DW) had a similar tendency with these determined by FW (Table 1). The shoot heights of two cultivars were both inhibited by Pi deficiency, but not significantly. Reversely, the root lengths under Pi deficiency were both longer than these under sufficient Pi condition. Remarkably, the increase of root length was significant in KN199, but not in CS (Table 1). In short, compared to the low-Pi sensitive cultivar CS, KN199 was more tolerant to Pi deficiency with drastically increased root biomass and R/S ratio. 
Table 1

Growth, phosphate uptake, and phosphate utilization efficiency of the two cultivars under Pi deficiency

\begin{tabular}{|c|c|c|c|c|c|}
\hline \multirow[t]{2}{*}{ Traits $^{a}$} & \multirow[t]{2}{*}{ Tissues } & \multicolumn{2}{|c|}{ Chinese Spring (CS) } & \multicolumn{2}{|c|}{ Kenong199 (KN199) } \\
\hline & & $+\mathrm{Pi}$ & $-\mathrm{Pi}$ & $+\mathrm{Pi}$ & $-\mathrm{Pi}$ \\
\hline \multirow[t]{3}{*}{$\begin{array}{l}\text { Biomass (mg } \\
\mathrm{DW}^{\mathrm{b}} / \text { plant) }\end{array}$} & Shoot & $\begin{array}{l}252.7 \pm \\
40.1 \mathrm{a}\end{array}$ & $\begin{array}{l}207.4 \pm \\
27.1 \mathrm{~b}\end{array}$ & $171.2 \pm 5.0 b$ & $\begin{array}{l}158.9 \pm \\
18.5 b\end{array}$ \\
\hline & Root & $43.8 \pm 5.8 b c$ & $49.2 \pm 3.6 a b$ & $36.9 \pm 2.0 c$ & $53.3 \pm 7.7 \mathrm{a}$ \\
\hline & $\mathrm{R} / \mathrm{S}$ & $\begin{array}{l}0.207 \pm \\
0.017 \mathrm{~b}\end{array}$ & $\begin{array}{l}0.266 \pm \\
0.010 \mathrm{ab}\end{array}$ & $\begin{array}{l}0.236 \pm \\
0.026 a b\end{array}$ & $\begin{array}{l}0.298 \pm \\
0.078 a\end{array}$ \\
\hline \multirow[t]{2}{*}{ Length $(\mathrm{cm})$} & Shoot & $35.7 \pm 1.9 a$ & $32.8 \pm 2.0 \mathrm{a}$ & $28.2 \pm 2.7 b$ & $27.7 \pm 3.8 b$ \\
\hline & Root & $32.6 \pm 1.9 b$ & $33.6 \pm 3.7 \mathrm{~b}$ & $34.9 \pm 2.9 b$ & $38.9 \pm 1.8 a$ \\
\hline \multirow{2}{*}{$\begin{array}{l}\text { Total P conc. }{ }^{c}(\mathrm{mg} \mathrm{P} / \mathrm{g} \\
\text { DW) }\end{array}$} & Shoot & $4.60 \pm 0.69 b$ & $1.21 \pm 0.10 \mathrm{~d}$ & $6.31 \pm 0.73 a$ & $2.12 \pm 0.16 c$ \\
\hline & Root & $6.46 \pm 0.15 b$ & $2.52 \pm 0.26 c$ & $7.99 \pm 0.37 a$ & $2.81 \pm 0.13 c$ \\
\hline \multirow[t]{2}{*}{$\begin{array}{l}\text { Soluble Pi conc. (ug P/g } \\
\text { FW }^{d} \text { ) }\end{array}$} & Shoot & $\begin{array}{l}282.40 \pm \\
33.44 \mathrm{~b}\end{array}$ & $\begin{array}{l}81.31 \pm \\
0.83 \mathrm{~d}\end{array}$ & $\begin{array}{l}449.72 \pm \\
18.81 \mathrm{a}\end{array}$ & $\begin{array}{l}146.07 \pm \\
18.30 \mathrm{c}\end{array}$ \\
\hline & Root & $\begin{array}{l}198.39 \pm \\
36.61 \mathrm{~b}\end{array}$ & $\begin{array}{l}43.68 \pm \\
6.46 \mathrm{c}\end{array}$ & $\begin{array}{l}290.73 \pm \\
40.95 a\end{array}$ & $\begin{array}{l}58.10 \pm \\
10.28 \mathrm{c}\end{array}$ \\
\hline \multirow[t]{2}{*}{ P content (mg P/plant) } & Shoot & $1.78 \pm 0.22 a$ & $0.38 \pm 0.03 c$ & $1.26 \pm 0.27 b$ & $0.45 \pm 0.88 c$ \\
\hline & Root & $0.55 \pm 0.04 a$ & $0.18 \pm 0.03 b$ & $0.50 \pm 0.13 a$ & $0.20 \pm 0.10 \mathrm{~b}$ \\
\hline \multirow[t]{2}{*}{$\mathrm{PUE}^{\mathrm{e}}$ (g DW/mg P) } & Shoot & $0.57 \pm 0.06 c$ & $2.68 \pm 0.22 a$ & $0.82 \pm 0.16 c$ & $2.27 \pm 0.36 b$ \\
\hline & Root & $1.81 \pm 0.14 b$ & $5.52 \pm 0.78 a$ & $2.09 \pm 0.48 b$ & $4.92 \pm 0.28 a$ \\
\hline \multicolumn{6}{|c|}{$\begin{array}{l}\text { Notes: }{ }^{a} \text { twelve-day-old wheat seedlings were grown on sufficient } \mathrm{Pi}(+\mathrm{Pi}) \text { solution or deficient } \mathrm{Pi}(-\mathrm{Pi}) \\
\text { solution for seven days. Data are means } \pm \mathrm{SD}(n=4) \text {, and different letters indicate significant } \\
\text { differences }(p<0.05) \text {. One-way ANOVA was used for analysis using Duncan's multiple range test. }{ }^{\mathrm{b}} \\
\text { DW: dry weight; }{ }^{\mathrm{c}} \text { conc.: concentration; }{ }^{\mathrm{d}} \mathrm{FW} \text { : fresh weight; }{ }^{\mathrm{e}} \text { PUE: phosphate utilization efficiency }\end{array}$} \\
\hline
\end{tabular}

\section{KN199 had great adaptation in root architecture under Pi deficiency}

For the massive increase of wheat root biomass in response to Pi deficiency, the global root architecture of the two cultivars was further analyzed. Pi deficiency induced the root growth, which was much more apparent in KN199 than that in CS (Fig. 2). The total root length of KN199 significantly increased by $44 \%$ after Pi deficiency treatment (Table 2). And the total root surface area and total root volume also significantly increased. However, the increases in these traits induced by Pi deficiency were not significant in CS. The average diameter of roots did not significantly change in the two cultivars. The number of root tips significantly increased in CS under Pi deficiency, but only significantly in KN199. Thus, the increase of root biomass in CS under Pi deficiency was mainly due to the increase of root tip number; the 
enormous increase of root biomass in KN199 contributed to the enhancement of total root length, total root surface area, and total root volume. Phosphorus is immobile in soils, so the root development with longer root length and greater root surface area is crucial for absorbing more Pi, particularly in the low-Pi environments.

Table 2

Phenotypic evaluation of global root morphology of the two wheat cultivars under Pi deficiency

\begin{tabular}{|c|c|c|c|c|}
\hline \multirow[t]{2}{*}{ Traits $^{a}$} & \multicolumn{2}{|l|}{ CS } & \multicolumn{2}{|l|}{ KN199 } \\
\hline & $+\mathrm{Pi}$ & $-\mathrm{Pi}$ & $+\mathrm{Pi}$ & $-\mathrm{Pi}$ \\
\hline Total root length $(\mathrm{cm})$ & $361 \pm 40 b$ & $411 \pm 42 b$ & $362 \pm 25 b$ & $522 \pm 61 a$ \\
\hline $\begin{array}{l}\text { Total root surface area } \\
\left(\mathrm{cm}^{2}\right)\end{array}$ & $35.95 \pm 5.56 b$ & $42.57 \pm 7.20 \mathrm{ab}$ & $37.88 \pm 2.55 b$ & $52.68 \pm 7.75 a$ \\
\hline Total root volume $\left(\mathrm{cm}^{3}\right)$ & $\begin{array}{l}0.285 \pm \\
0.058 b\end{array}$ & $0.300 \pm 0.019 b$ & $0.316 \pm 0.041 b$ & $0.423 \pm 0.076 a$ \\
\hline Average diameter $(\mathrm{mm})$ & $\begin{array}{l}0.316 \pm \\
0.017 \mathrm{a}\end{array}$ & $0.328 \pm 0.033 a$ & $0.334 \pm 0.025 a$ & $0.320 \pm 0.012 a$ \\
\hline Number of root tips & $1378 \pm 148 b$ & $1735 \pm 331 a$ & $1353 \pm 139 b$ & $1662 \pm 160 \mathrm{ab}$ \\
\hline \multicolumn{5}{|c|}{$\begin{array}{l}\text { Note: }{ }^{a} \text { the value for each trait is determined per plant. Data are means } \pm \text { SD }(n=4) \text {, and different } \\
\text { letters indicate significant differences }(p<0.05) \text {. One-way ANOVA was used for analysis using } \\
\text { Duncan's multiple range test }\end{array}$} \\
\hline
\end{tabular}

\section{KN199 showed higher Pi concentrations in shoots than CS under Pi deficiency, but not in roots}

The P uptake and PUE in shoots and roots of the two wheat cultivars in response to Pi deficiency were displayed in Table 1. Under $+\mathrm{Pi}$ and $-\mathrm{Pi}$ conditions, the shoot soluble $\mathrm{Pi}$ and total $\mathrm{P}$ concentrations of KN199 were all significantly higher than these of CS. Particularly, the shoot soluble Pi concentration in KN199 under - Pi was almost two folds higher than that in CS. But, these variations in roots were small. Under P sufficient condition, KN199 still showed significantly higher levels of soluble Pi and total P concentrations in roots than these in CS. While under Pi deficiency, the two cultivars had no significant variations in the root soluble $\mathrm{Pi}$ and total $\mathrm{P}$ concentrations. For the high biomass of $\mathrm{CS}$ under $+\mathrm{Pi}$ condition, the shoot P content of KN199 was lower than that of CS. Under Pi deficiency, the shoot P content of KN199 was higher than that of CS. So, KN199 had higher PAE both under sufficient Pi and deficient Pi conditions. Under limited P supply, high Pi level in shoots is a higher priority than that in roots in KN199. Pi deficiency increased the shoot and root PUE (Biomass production per unit of $P$ ) in both cultivars. The increase in shoots was more significant in CS (4.7 folds) than that in KN199 (2.8 folds). Also, the variation in roots between the two cultivars was not significant. Thus, the low-Pi tolerant cultivar 
KN199 had higher PAE and preferentially maintained high total Pi concentration in shoots in response to Pi deficiency.

\section{The genes related to miR399-mediated signaling were differentially regulated in shoots, but not in roots}

To elucidate the molecular mechanism of the favorable adaptations in root traits and $\mathrm{P}$ uptake in the lowPi tolerant cultivar KN199, we firstly analyzed the gene expression related to the miR399-mediated signaling (PHR1-IPS1-miR399-UBC24/PHO2 signaling cascade), TaPHR1, TaIPS1, TaSPX3, and TaPHO2 (Fig. 3). PHR1, an MYB-type transcription faction, was a critical factor in regulating the expression of several downstream phosphate starvation responsive genes [32]. Under Pi deficiency, the TaPHR1 abundance in shoots showed opposite changes between the two cultivars, both not significantly. The TaPHR1 abundance in the roots was significantly increased by Pi deficiency in KN199, but which did not change in CS. Unlike the small changes of TaPHR1, the expression levels of TaIPS1 and TaSPX3 in shoots and roots were all dramatically increased by Pi deficiency in the two cultivars. Remarkably, the upregulation in the shoots of KN199 was much lower than these in CS, but they almost had no significant differences between the two cultivars. The expression levels of $\mathrm{TaPHO} 2$ in roots were much higher than those in shoots. Under - Pi condition, the TaPHO2 abundances in CS significantly increased in shoots and roots, but which in KN199 significantly increased only in roots. In short, these key genes related to miR399-mediated signaling were much greater induced in the shoots of CS than those in KN199, while these genes in roots had no significant differential expression between the two cultivars. These differential regulations in shoots between the two cultivars were consistent with the changes in total $P$ and $\mathrm{Pi}$ concentration. The Pi deficiency-induced variations in shoot total $\mathrm{P}$ and $\mathrm{Pi}$ concentrations were larger than that in roots. Under P deficiency, KN199 could maintain higher shoot total P and Pi concentrations than CS. These suggested that the different adaptations in the root architecture of the two cultivars was probably not contributed to the differential regulation of the miR399-mediated signaling pathway.

\section{The genes related to hormone-mediated signaling were differentially regulated in roots}

Besides miR399-mediated signaling, many hormones have been reported involved in Pi starvation signaling pathways, such as auxin, ethylene, GA, and JA. Changes in Pi availability alter hormone production, sensitivity, and transport, and then affect RSA $[11,15]$. The transcriptional levels of genes associated with hormone metabolism and transport were tested in the roots of the two cultivars (Fig. 4). Tryptophan decarboxylase (TDC) [33] and PIN-FORMED auxin efflux transporters (PIN) [34] are key proteins involved in auxin biosynthesis and transport, respectively. The TaTDC and TaPIN9 abundances were significantly increased by Pi deficiency in roots (Fig. 4, a and b), however, there was no significant difference between the two cultivars. The transcript abundances of genes involved in ethylene synthesis, 1-aminocyclopropane-1-carboxylic acid synthase 7 (ACS7) and 1-aminocyclopropane-1-carboxylic acid oxidase 2 (ACO2) [35], were also significantly increased under Pi stress, except TaACS7 in KN199 (Fig. 4, c and d). The increase of the TaACS7 abundance in the roots of KN199 was slight. Besides, the upregulation of $\mathrm{TaACO} 2$ in KN199 was lower than that in CS. Compared with CS, the induction of ethylene 
biosynthesis by Pi deficiency inhibited in KN199. GA 3-oxidase (GA3ox) and lipoxygenase (LOX) are essential proteins involved in the GA and JA biosynthesis, respectively [36, 37]. The expression levels of TaGA3OX2 and TaLOX8 were low in roots. However, the TaGA3ox2 and TaLOX8 abundances were all significantly induced in the roots of the two cultivars (Fig. 4, e and f). Although these two genes were increased about 2-3 folds by Pi deficiency in the two cultivars, the expression levels in KN199 were about two-fold higher than these in CS. Pi deficiency significantly induced the biosynthesis of these hormones in roots, and the genes associated with ethylene, GA, and JA had differential regulation between the two cultivars. These indicated that the hormone-mediated signaling is probably involved in the different changes of the Pi deficiency-induced root traits.

\section{The genes associated with root development were differentially regulated in roots}

Further, the expression of several genes related to root development was determined in the two cultivars. E2F-related (E2F) transcription factors regulated root cell cycle entry and DNA synthesis [38]. A moderate level of TaE2f was detected both in roots and shoots of the two cultivars (Fig. 5, a and b). Under Pi deficiency, the TaE2 $f$ abundance in the roots of CS was significantly increased, while which was slightly decreased in KN199. In shoots, the TaE2f abundances were both down-regulated in the two cultivars. The SOMATIC EMBRYOGENESIS RECEPTOR KINASE1 (SERK1) is a member of the Leu-rich repeat, receptorlike kinase protein family, and plays a critical role in root differentiation [39]. The expression levels of TaSERK1 were relatively low in the roots of two cultivars (Fig. 5, c). Under Pi deficiency, the TaSERK1 abundances were remarkably up-regulated about 7-folds in KN199, while which had no obvious change in CS. In shoots, the TaSERK1 abundances were both up-regulated in the two cultivars. And the expression level in KN199 was much higher than that in CS. Expansins are involved in plant development, especially root development [40]. The TaEXPB23 abundance in roots both increased under Pi deficiency in the two cultivars (Fig. 5, d). The increase fold in KN199 was also much higher than that in CS. The TaEXPB23 abundances were slightly induced in shoots, and they were no differences between the two cultivars. So, these genes associated with root development were mainly differentially regulated by Pi deficiency between the roots of two cultivars. It was consistent with different Pi deficiency responses in root traits.

\section{The expression levels of the phosphate transporter 1 (PHT1) genes were greatly induced in the roots of KN199}

The PHT1 family genes mediate P uptake and re-mobilization in wheat [41]. We detected the expression levels of TaPHT1.1/1.9 and TaPHT1.3 under + Pi and - Pi conditions. The TaPHT1.1/1.9 gene was root special. The expression levels of TaPHT1.1/1.9 were moderate, and which of TaPHT1.3 were high (Fig. 6, $a$ and b). Under Pi deficiency, the TaPHT1.1/1.9 and TaPHT1.3/1.4 abundances were significantly upregulated in two cultivars. The TaPHT1.1/1.9 expression level in KN199 was higher than that in CS. Likely, the up-regulation of TaPHT1.3/1.4 in KN199 was much stronger than that in CS. The higher induction of these PHT1 genes in the roots of KN199 probably contributed to the uptake of more Pi, maintaining the high level of total $\mathrm{P}$ and $\mathrm{Pi}$ concentration in shoots under Pi deficiency. 
The metabolic changes in roots were simultaneously investigated using gas chromatography-mass spectrometry (GC-MS). A total of 98 metabolite features were detected in the roots of the two cultivars. However, only 44 metabolites were identified (Additional file 1: Figure S1 and Additional file 2: Table S1). To find the different performances of the two cultivars in response to Pi deficiency, heatmap analysis of the 44 identified metabolites was conducted. Pi starvation changed the abundances of root metabolites, and more remarkable changes were observed in the roots of KN199 (Fig. 7 and Additional file 3: Table S2). Twenty-five metabolites in roots were significantly changed by Pi stress in the two cultivars, including ten organic acids, four amino acids, and 11 other compounds (Table 3). Principle component analysis (PCA) was performed based on these 25 metabolites (Fig. 8 and Additional file 4: Table S3). PC1 and PC2 accounted for approximately $73.8 \%$ of the total variation. Under + Pi condition, the samples of the two cultivars could not separate well, while they separated well under - Pi condition. The samples of KN199 under + Pi and - Pi conditions could separate; however, the samples of CS did not separate. It indicated that the Pi deficiency caused more significant changes in KN199 than CS in root metabolites. The main metabolites contributing to the PC1 included threonine, glycine, L-valine, fumaric acid, etc. 
Table 3

Metabolite variations in the roots of the two wheat cultivars under Pi deficiency

\begin{tabular}{|c|c|c|c|c|c|}
\hline \multirow[t]{2}{*}{ Metabolite name } & \multicolumn{2}{|c|}{$\log _{2}(-P i /+P i) a$} & \multirow[t]{2}{*}{ Metabolite name } & \multicolumn{2}{|c|}{$\log _{2}(-P i /+P i)$} \\
\hline & CS & KN199 & & CS & KN199 \\
\hline \multicolumn{3}{|l|}{ Organic acids } & \multicolumn{3}{|l|}{ Other compounds } \\
\hline Acetoacetic acid & 0.58 & $1.08 *$ & Arabinofuranose & $-3.89 * \star \star$ & 0.66 \\
\hline Citric acid & 0.19 & $0.74 *$ & Arbutin & $-2.07 *$ & -0.53 \\
\hline Fumaric acid & -0.14 & $2.79 \star \star \star$ & Azelaic acid & 0.03 & $0.55^{\star \star}$ \\
\hline Lactic acid & $0.36^{*}$ & $0.68 *$ & D-Erythronolactone & $-0.96^{\star}$ & 1.14 \\
\hline Malic acid & 0.35 & $0.80 * *$ & Diacetone alcohol & $1.61 \star \star$ & 0.08 \\
\hline Oxalic acid & ND & $1.6 * \star \star$ & D-Xylofuranose & 0.39 & 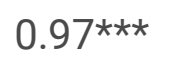 \\
\hline \multicolumn{3}{|l|}{ Amino acids } & D-Xylono-1,4-lactone & -0.20 & $1.18^{\star}$ \\
\hline 4-Aminobutanoic acid & 1.02 & $3.11 \star \star$ & Erythritol & 0.72 & 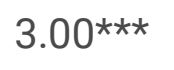 \\
\hline L-Pyroglutamic acid & -0.59 & $1.98 * \star$ & Glyceric acid & -0.91 & $1.76^{\star \star}$ \\
\hline Glycine & 0.69 & $3.07 \star \star \star$ & Glycerophosphoric acid & $-0.92^{\star}$ & 0.08 \\
\hline Valine & $0.60 *$ & $2.72^{\star \star}$ & Monoethanolamine & -0.46 & $0.70 *$ \\
\hline \multirow[t]{3}{*}{ Threonine } & 2.1 & $3.89 *$ & Phosphoric acid & $-3.46^{* * \star}$ & $-2.88 * \star \star$ \\
\hline & & & Stearic acid & 0.01 & $0.19 *$ \\
\hline & & & Sucrose & $-0.66^{\star}$ & 0.17 \\
\hline \multicolumn{6}{|c|}{ 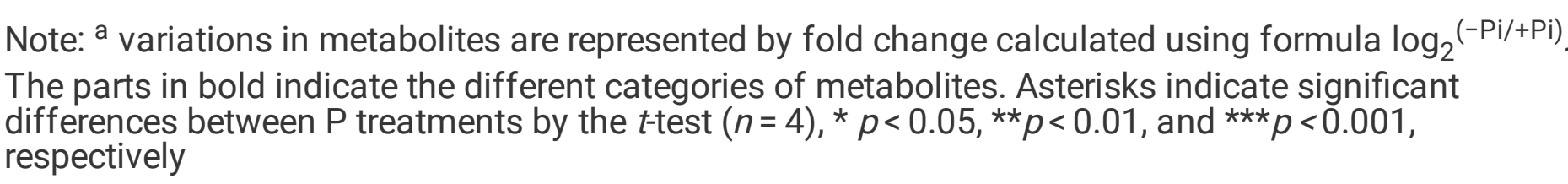 } \\
\hline
\end{tabular}

Under Pi deficiency, only three and six metabolites in the roots of CS showed significant up-regulated and down-regulated, respectively (Table 3 ). Meanwhile, 18 metabolites significantly accumulated in the roots of KN199. Only the phosphoric acid concentration severely decreased under - Pi condition. Overall, $\mathrm{Pi}$ deficiency caused greater increases of metabolites in the roots of KN199 than CS. In particular, the accumulations of amino acids were pronounced. KN199 accumulated higher contents of threonine, glycine, valine, and L-Pyroglutamic acid in response to Pi deficiency (Table 3). However, in CS, only the valine concentration showed a significant increase. Similarly, the accumulations of organic acids also significantly increased in the roots of KN199. The concentrations of fumaric acid, oxalic acid, citric acid, malic acid, and lactic acid were increased 1.60-6.93 folds by Pi deficiency. However, the concentrations 
of these metabolites were not significantly changed in the roots of CS, except lactic acid. Besides, the arabinofuranose, arbutin, D-erythronolactone, glycerophosphoric acid, and sucrose concentrations were significantly decreased by Pi deficiency in CS. While these metabolites did not significantly change in KN199. Thus, the accumulation of primary metabolites, amino acids and organic acids, was remarkably enhanced in KN199 by Pi deficiency.

\section{Discussion}

Pi deficiency causes a severe reduction in growth and crop yield. The development of wheat cultivars with low-Pi tolerance and high-Pi efficiency is important for optimal fertilizer use, food security, and agricultural sustainability. The wheat cultivar KN199 showed high stress tolerance and production under low P input in long-term field experiments [31]. Coincidently, KN199 displayed low-Pi tolerance in the seedling stage under hydroponic conditions. By comparing with low-Pi sensitive cultivar CS, we revealed the adaption and the relevant molecular mechanisms of low-Pi tolerant cultivar KN199 in this study.

\section{The low-Pi tolerance of KN199 contributed to great root architecture adaptation}

High-yield cultivars were mostly obtained by selecting the above-ground organs, whereas the belowground roots are generally neglected. Undoubtedly, root traits played vital roles in anchorage, water, nutrient uptake, environmental stress tolerance, and productivity [6]. In our study, the most obvious phenotypic variation in response to Pi deficiency between the two wheat cultivars was modification in roots. Under Pi deficiency, the total root length and root biomass greatly increased in KN199 with greater total surface area and total volume. This adaptation in roots was crucial for absorbing more immobile $\mathrm{Pi}$ in soil. A study based on 215 wheat genotypes demonstrated that genotypes with a greater ratio of seminal lateral root length to seminal axis root length under reduced $P$ condition had a higher root $P$ concentration [42]. Compared to low-P sensitive lines, the tolerant barley lines revealed greater root plasticity in the terms of lateral root length under low-P stress [43]. The adaptation manner in wheat was different from some other plants. In $A$. thaliana, the primary root length reduced under the limiting $\mathrm{Pi}$ condition, but the formation of lateral roots and root hairs increased [7]. In common bean, total root length and lateral root number greatly reduced under Pi deficiency [44]. The root traits observed in wheat were more similar to those in barley. After ten days of Pi deficiency, the barely seedlings had more lateral roots, but shorter primary roots [21]. The selection and breeding of high PUE cultivars by root performance was blocked by the difficulty in observing root traits. Ren et al. reported quantitative trait locus pyramiding based on hydropic culture for root traits provided practical information for development of wheat varieties with large and deep root system and efficient $\mathrm{P}$ uptake [45]. However, the effect of $\mathrm{Pi}$ deficiency on root development is complex, species-specific, and cultivar dependent [5], breeding Pdeficiency-tolerant wheat cultivars is still challenging. The exploration of molecular regulation and key components in response to low Pi response could provide crucial clues for genetic engineering approaches to enhance PAE.

\section{Molecular regulation for the root adaptation in response to Pi deficiency}


The expression of Pi-starvation response genes revealed the possible regulatory mechanisms for the lowPi tolerance of KN199. The genes related to the miR399-mediated signaling pathway had no significant differences between the roots of two cultivars, while the genes involved in hormones (ethylene, GA, and JA) biosynthesis and root development were differentially expressed between the two cultivars. Ethylene synthesis had implicated in changing the RSA in response to Pi deficiency in plants. In Arabidopsis, inhibition of ethylene production decreased the elongation of roots in low Pi conditions [18]. In common bean, ethylene production per $\mathrm{g}$ dry matter in roots was significantly higher under Pi-deficient conditions with reduction of root mass and lateral root density [44]. In wheat, the genes involved in ethylene biosynthesis were significantly increased under Pi deficiency. However, the increase of TaACS7 was not obvious in KN199 under Pi deficiency. The inhibition of ethylene production may increase the root elongation in KN199. GA stimulated root growth by promoting the destruction of the repressors, a family of nuclear growth-repressing DELLA proteins [46]. In Arabidopsis, Pi starvation caused a decrease in the level of bioactive GA and related genes involved in GA metabolism, triggering the inhibition of root and shoot growth and accumulation of anthocyanin [17]. While in wheat, the TaGA3ox2 gene involved in GA biosynthesis was both induced in two cultivars, which enhanced the active of GA, and then increased root biomass under $\mathrm{Pi}$ deficiency. Transcriptome analyses had demonstrated that genes in hormone biosynthesis and responses were regulated under Pi deficiency $[19,47,48]$. However, evidence for the specificity and direct association of certain hormones needs further studies, particularly wheat.

Besides, the genes associated with root development, TaE2f, TaSERK1, and TaEXPB23, were also differentially regulated in roots between the two cultivars. In Arabidopsis, transcription factor E2FC negatively regulates lateral root formation [38]. The transgenic plant with reduced $E 2 f c$ mRNA levels developed organs with more but smaller cells and increased proliferative activity. The expression regulation of TaE2f in response to Pi deficiency was consistent with root morphological changes in the two cultivars. SERKs control somatic embryogenesis and root formation in plants $[39,49]$.

Overexpression of TaSERK1 in Arabidopsis increased plant height, root length, and even larger silique size and increased seed yield [50]. Expansins may also play roles in root architecture in response to $\mathrm{Pi}$ deficiency. The up-regulation of expansin genes in Stylosanthes participated in root growth under low $P$ condition [51]. GMEXPB2, a vegetative $\beta$-expansin gene, encodes a secretory protein on the cell wall and is highly induced by Pi starvation in soybean [52]. Overexpressing GmEXPB2 in Arabidopsis increased root cell division and elongation, enhanced plant growth, and $\mathrm{P}$ uptake. Consistently, the significantly increased expression of TaSERK1 and TaEXPB2 in roots of KN199 contributed to the enhanced root development under Pi deficiency.

\section{Molecular Regulation For The Pi Uptake Under Pi Deficiency}

The total P and Pi concentrations could preferentially maintain at the higher level in shoots of KN199 than that in CS. Results showed that the expression of genes involved in the miR399-mediated signaling pathway was differentially expressed in shoots of the two cultivars. miR399 is specifically response to Pi stress as a systemic signal $[11,13]$. It directs the cleavage of PHO2 mRNA encoding a ubiquitin conjugating E2 enzyme. $\mathrm{PHO} 2$ regulates Pi transport through ubiquitin-mediated protein degradation. An 
Arabidopsis pho2 mutant over-accumulated Pi in leaves under Pi stress [13]. The expression level of $\mathrm{TaPHO} 2$ significantly increased in shoots of CS under Pi deficiency, while the abundance of $\mathrm{TaPHO} 2$ in the shoots of KN199 did not significantly change. Thus, the inhibition of TaPHO2 may contribute to the high Pi concentration in the shoots of KN199. Similarly, the up-regulation of TaIPS1 and TaSPX3 was also inhibited in the shoots of KN199. In A. thaliana, overexpression of AtIPS1 increased the accumulation of the miR399 target PHO2 mRNA, resulting in reducing shoot Pi content [53]. In barely, The P-acquisitionefficient cultivar had a low abundance of IPS1 [54]. These results indicate that low expression of IPS genes resulted in highly efficient uptake and Pi accumulation in shoots. SPXs mainly reported as a negative regulator in Arabidopsis and rice in response to Pi stress [55]. In rice, nuclear-localized SPX1 and SPX2 were Pi-dependent inhibitors for the activity of OsPHR2 by inhibiting its binding to the PHR1binding sequence, P1BS motif [56]. Compared with wide type plants, Osspx1 and Osspx2 single mutants had a significantly higher Pi concentration in high Pi conditions. Consistent with the above studies, the high Pi concentration in the shoot of KN199 partly contributed to the weak expression of TalPS1 and TaSPX3. Besides, the genes TaPHT1.1/1.9 and TaPHT1.3 were stronger induced in KN199 under Pi stress, which absorb and transport more Pi. Campos et al. revealed that the higher PAE of the wheat cultivar Crac was associated with an improved IPS1-miR399-PHO2 signalling in roots through a finetuning modulation of $\mathrm{PHO} 2$ activity [57]. In sum, the regulation in miR399-mediated signaling pathway, together with the induction of TaPHT1 genes, kept KN199 maintain high total P and Pi concentration under Pi deficiency.

\section{Accumulations of the primary metabolites revealed the accelerated carbon and nitrogen flow under $\mathrm{Pi}$ stress}

For in-depth analyzing the changes in roots, nonbiased metabolite profiling using GC-MS revealed that about $56 \%$ of identified metabolites differentially accumulated between two wheat cultivars. Most of the primary metabolites detected in the roots increased in response to Pi deficiency. And more remarkable changes were observed in KN199 than these in CS. The primary metabolic adaptations in response to Pi deficiency were in agreement with previous analyses in common bean [23]. Most of amino acids, nitrogen compounds, some organic acids, polyols, and sugars were increased under Pi deficiency, only eight metabolites were decreased in the roots of common bean. Strikingly, organic acids of the TCA cycle were significantly induced under Pi deficiency in the roots of the wheat cultivars, especially in KN199 (Fig. 9). The result was consistent with that observed in the roots of wheat, tomato, chickpea, and white lupin [58]. The malic acid, citric acid, and malonic acid tested in these plants were almost all significantly increased. In barley, the levels of malate, citrate, and a-ketoglutarate were also increased under ten days of $\mathrm{Pi}$ deficiency treatment [21]. But after 17 days Pi deficiency treatment, these organic acids in the roots of barley were slightly reduced, indicating the shortage in carbohydrate supply in severely Pi-deficient plants. Some distinct changes were detected in some other plants. In rice, the concentration of lactic acid in roots was increased, while malic acid and citrate were decreased under Pi deficiency [20]. In common bean, different organic acids had different variations. Succinic acid and malic acid were increased and decreased under Pi deficiency, respectively [23]. The abundances of organic acids exhibited large variation between the low-Pi tolerant and low-Pi sensitive maize cultivars [22]. Thus, it appears that 
metabolic changes in the TCA cycle in response to Pi deficiency differ among plant species and plant cultivars. The increased accumulation of primary metabolites in KN199 indicated that the acceleration of carbon flow in adapt to moderate low-Pi stress of seven days in wheat.

In many plants, root secrets organic acids into the rhizosphere to enhance Pi solubilization and release fixed $\mathrm{P}$ in soils [5]. However, in our study, we tried to collect the root exudates of the two wheat cultivars in response to Pi deficiency. However, the secreted malic acid, lactic acid, acetic acid, citric acid, fumaric acid, and succinic acid were extremely low. Neumann et al. reported the increased secretion of malic acid, citric acid, and malonic acid secreted in chickpea and white lupin, but not in wheat. [58]. In wheat, only malic acid and low oxalic acid were detected in tested nine organic acids. Our results revealed that little root exudation was induced by Pi deficiency in wheat, although organic acids highly accumulated in the roots.

Several amino acids accumulated in the two wheat cultivars under Pi stress and the increase was also much more pronounced in the Pi-tolerant cultivar KN199 (Fig. 9). Consistent with these observation in some other plants, Pi deficiency induced the accumulation of most amino acids detected in wheat. In the roots of common bean and soybean, most of the amino acids increased under Pi stress, such as threonine, arginine, lysine, and serine $[23,24]$. This accumulation of amino acids in roots possibly due to increased protein degradation and repressed protein synthesis under Pi stress. In the roots of severely Pideficiency barely, the amino acids involved in ammonium metabolism, glutamine, asparagine, and putrescine, were sharply increased, leading to an increased level of ammonium and alteration in ammonium assimilation [21]. The intracellular accumulation of amino acids could also be used as the source or intermediates of carbon and nitrogen metabolism under Pi deficiency. Especially, valine and threonine, which share the synthetic pathway with branched chain amino acids, displayed the most significant change. These amino acids were common responses under abiotic stresses would be an alternative electron donor for mitochondrial electron transport and an important alternative respiratory substrate $[59,60]$.

\section{Conclusions}

In summary, our results demonstrated a suite of Pi deficiency responses ranging from root morphology, physiology, gene expression, and metabolites between the two contrasting cultivars. To adapt $\mathrm{Pi}$ deficiency environment, the low-Pi tolerant cultivar KN199 developed more favorable root traits for $P$ uptake, with larger biomass and longer total root length. The total $\mathrm{P}$ and $\mathrm{Pi}$ concentrations could preferentially keep at a higher level in shoots without a significant decrease in shoot biomass. These adaptations probably contributed to the regulation of genes related to the hormone-mediated signaling, root development, $\mathrm{P}$ transporters in roots, and miR399-mediated signaling in shoots. The organic acids in TCA and amino acids also accumulated as the preferred storage metabolites in the roots of KN199 for enhanced carbon and nitrogen metabolism. The understanding of mechanisms through the two contrasting cultivars (the wild and cultivated species) would help to design of more effective breeding and genetic engineering strategies to produce highly PAE crop. 


\section{Methods}

\section{Wheat cultivars and growth conditions}

Bread wheat (Triticum aestivum L.) cultivar KN199 and CS were used in this study. Seeds of these two cultivars were provided by Professor Xiuying Kong from Chinese Academy of Agricultural Sciences, China. CS was the model wheat, which widely studied [61]. KN199 was derived from a cross between Kn9204 (a 1RS/1BL translocated and derivative of wheat Thinopyrum ponticum partial amphiploid) and Shi4185 (developed by Institute of Genetics and Developmental Biology, Chinese Academy of Sciences) [30]. The seeds were surface-sterilized with $10 \% \mathrm{H}_{2} \mathrm{O}_{2}$ and then germinated on filter paper saturated with distilled water in darkness at $25^{\circ} \mathrm{C}$ for one day. The seeds were transplanted into a plastic net suspended on a plastic container $(1 \mathrm{~L})$ filled with $0.5 \mathrm{mM} \mathrm{CaCl}_{2}$ solution $(\mathrm{pH} \mathrm{4.5)}$ for three days and transplanted into 1/4 modified Hoagland solution. The 12-day-old seedlings were grown on Pi-sufficient or Pi-deficient 1/4 modified Hoagland nutrient solution for seven days. The modified 1/4 Hoagland solution was composed of $(\mu \mathrm{M}): \mathrm{Ca}\left(\mathrm{NO}_{3}\right)_{2} \cdot 4 \mathrm{H}_{2} \mathrm{O}(2000), \mathrm{MgSO}_{4} \cdot 7 \mathrm{H}_{2} \mathrm{O}(650), \mathrm{KH}_{2} \mathrm{PO}_{4}(250), \mathrm{K}_{2} \mathrm{SO}_{4}(750), \mathrm{KCl}(100), \mathrm{MnSO}_{4} \cdot \mathrm{H}_{2} \mathrm{O}$ (10), $\mathrm{CuSO}_{4} \cdot 5 \mathrm{H}_{2} \mathrm{O}(0.1), \mathrm{ZnSO}_{4} \cdot 7 \mathrm{H}_{2} \mathrm{O}(1), \mathrm{H}_{3} \mathrm{BO}_{3}(1),\left(\mathrm{NH}_{4}\right)_{6} \mathrm{MoO}_{24} \cdot 4 \mathrm{H}_{2} \mathrm{O}(0.05)$, and Fe(III)-EDTA (40). The Pi sufficient nutrient solution contained $250 \mu \mathrm{M} \mathrm{KH}_{2} \mathrm{PO}_{4}$, and Pi deficient nutrient solution did not contain $\mathrm{KH}_{2} \mathrm{PO}_{4}$ with an additional $250 \mu \mathrm{M} \mathrm{KCl}$. The $\mathrm{pH}$ was adjusted to 6.0. The solutions were replenished regularly at three-day intervals. The seedlings were grown in a temperature-controlled growth chamber with a $14-\mathrm{h} / 26^{\circ} \mathrm{C}$ day and a $10-\mathrm{h} / 23^{\circ} \mathrm{C}$ night cycle, a light intensity of $300 \mu \mathrm{mol} \mathrm{m}{ }^{-2} \mathrm{~s}^{-1}$, and a relative humidity of $60 \%$. All experiments in this study were conducted independently at least twice.

\section{Soluble Pi concentration and total P concentration}

Shoots and roots of seedling were sampled respectively, weighed, and homogenized in liquid nitrogen to determine the soluble Pi concentration. Pi was extracted with $8 \mathrm{~mL}$ of $5 \%(\mathrm{v} / \mathrm{v})$ sulphuric acid $(5 \mathrm{M})$ solution. The supernatants were obtained by centrifugation at $12000 \mathrm{~g}$ for $15 \mathrm{~min}$ for Pi determination. To determine the total $\mathrm{P}$ concentration, the dried samples were ground to powders and digested with 5 $\mathrm{mL} \mathrm{H}_{2} \mathrm{SO}_{4}$ for three hours at $150^{\circ} \mathrm{C}$. Meantime, $\mathrm{H}_{2} \mathrm{O}_{2}$ was added to make the samples properly digest. The soluble $\mathrm{Pi}$ and total $\mathrm{P}$ concentrations were measured using the molybdate blue-colorimetric method [62]. The diluted samples ( $\mathrm{pH}$ adjusted) were mixed with $15 \%(\mathrm{w} / \mathrm{v})$ fresh ascorbic acid dissolved in ammonium molybdate (pH 5.0) and then incubated at $37^{\circ} \mathrm{C}$ for $30 \mathrm{~min}$. The absorbance at $650 \mathrm{~nm}$ was recorded. The Pi and total P concentrations were calculated using FW and DW normalization, respectively.

\section{Global Root morphology analysis}

To characterize the global root morphology, the harvested roots were dispersed on a clear perspex tray with water and scanned using a root system scanner (EPSON Expression 1600, Seiko EPSON Corp., Japan). The images were analyzed using WinRHIZO software (WIN MAC, Regent Instruments Inc., Canada; http://www.regentinstruments.com/). WinRHIZO output included total root length per plant in 
centimeter $(\mathrm{cm})$, total surface area in $\mathrm{cm}^{2}$, average diameter in millimeter $(\mathrm{mm})$, total volume per plant in $\mathrm{cm}^{3}$, and the number of tips.

\section{Gene expression analysis}

Total RNA was extracted from homogenized frozen shoots or roots $(50 \mathrm{mg})$ according to the operations manual supplied by Plant RNA Kit (TianGen, OSR-M610) and convert into cDNAs using Prime Script reverse transcriptase (Toyobo, FSQ-101). The quality and quantity of RNA were assessed using agarose gel electrophoresis and the NanoDrop 2000 (Thermo Fisher Scientific, USA). The quantitative real-time PCR reactions were performed in a $10 \mu \mathrm{L}$ reaction volume containing $0.01 \mathrm{ug}$ of $\mathrm{cDNA}, 0.2 \mu \mathrm{M}$ of each primer, and $5.0 \mu \mathrm{L}$ of SYBR Green Realtime PCR Master Mix (Toyobo, QPK-201). Three technical replicates were conducted for each cDNA sample. Three biological replicates were used for transcript analysis. The relative expression levels of genes were calculated according to the $2-\triangle \triangle \mathrm{Ct}$ method [63]. The wheat adenine phosphoribosyltransferase (TaAPT1) gene was used as reference gene. The primer sequences for all genes tested are listed in Additional file 5: Table S4.

\section{GC-MS analysis of intracellular metabolites in roots}

The metabolite extraction and derivatization were performed as described by Ganie et al. [22]. The homogenized frozen roots $(100 \mathrm{mg})$ were extracted with pre-cooled solvents, isopropanol: acetonitrile: water (3:3:2) and chloroform: water (1:2). The methanol/water phase was dried by vacuum centrifugation (Concentrator Plus, Eppendorf, Germany) overnight. After carbonyl moieties were protected by methoximation, the acidic protons were derivatized with $70 \mu \mathrm{L} \mathrm{N}$-methyl-N-trimethylsilyl trifluoroacetamide (Sigma-Aldrich Co., USA) at $37^{\circ} \mathrm{C}$ for $90 \mathrm{~min}$. The trimethylsilyl samples were separated and analyzed using the GC-MS system (GC: Varian CP-3800, MS: Saturn 2200, USA) according to the method of Ganie [22]. Mass spectra were recorded from m/z 35 to 600 for trimethylsilyl derivatization. Compounds were identified by comparing them with the reference compounds in MainLib or Wiley Registry8e (Additional file 1: Figure S1 and Additional file 2: Table S1). Mass spectral matching was manually supervised, and matches were accepted with thresholds of match 700 . The areas of the identified metabolites were analyzed using MetaboAnalyst 4.0 online (https://www.metaboanalyst.ca/MetaboAnalyst/faces/home.xhtml) [64]. The remaining missing values were estimated using the Singular Value Decomposition method [65]. Log normalization was used for data transformation. Features were removed with $>51 \%$ missing values. The identified metabolites were comprehensively compared using the PCA and Heatmap analysis. The fold-change of metabolite between control and treatment was transformed by a logarithmic base of 2 .

\section{Statistical analysis}

Data represent means \pm SD of three biological replicates and subjected to a one-way ANOVA using IBM SPSS statistical software (version 22.0.0.0) for statistical analysis. The morphological, physiological, and gene expression analyses were repeated at least twice with one set of data shown in results. 


\section{Abbreviations}

+Pi/-Pi: Sufficient/deficient inorganic phosphate; ACO2: 1-Aminocyclopropane-1-carboxylic acid oxidase 2; ACS7: 1-Aminocyclopropane-1-carboxylic acid synthase 7; DW: Dry weight; E2F: E2F-related; FW: Fresh weight; GA: Gibberellin; GA3ox: GA 3-oxidase; GC-MS: Gas chromatography-mass spectrometry; JAs: Jasmonates; LOX: Lipoxygenase; P: Phosphorus; PAE: Phosphate acquisition efficiency; PCA: Principle component analysis; Pi: inorganic phosphate; PHO2: PHOSPHATE2; PHR1: Phosphate starvation response 1; PUE: Phosphate utilization efficiency; RSA: Root system architecture; SERK1: SOMATIC EMBRYOGENESIS RECEPTOR KINASE1; TCA: Tricarboxylic acid

\section{Declarations}

\section{Ethics approval and consent to participate}

Not applicable.

\section{Consent for publication}

Not applicable.

\section{Availability of data and materials}

All data generated or analyzed during this study are included in this published article and its supplementary information files.

\section{Competing interests}

The authors declare that they have no competing interests.

\section{Funding}

This study was supported by the National Key Research and Development Program of China (No. 2016YFD0200308), the Project of Priority and Key Areas, Institute of Soil Science, Chinese Academy of Sciences (No. ISSASIP1605 and ISSASIP1640), and the Open Project Program of State Key Laboratory of Crop Stress Biology for Arid Areas (No. CSBAA2020006). The funding body played no role in the design of the study and collection, analysis, and interpretation of the data and in writing the manuscript.

\section{Authors' contributions}

P.L. conceived and designed the research. L.Z. performed the experiments and data analyses. L.Z., P.L., Y.G.H., R.F.S., and M.R.K. revised the manuscript. All authors read and approved the final manuscript.

\section{Acknowledgements}


We are grateful to Professor Xiuying Kong (Chinese Academy of Agricultural Sciences, China) for kindly providing the seeds of wheat cultivars. We also thank Doctor Hatem Rouached (French National Institute for Agricultural Research, France) and Doctor Jorge Rodríguez-Celma (John Innes Centre, UK) for valuable suggestions and comments.

\section{Authors' information}

${ }^{1}$ State Key Laboratory of Soil and Sustainable Agriculture, Institute of Soil Science, Chinese Academy of Sciences, Nanjing 210008, China. ${ }^{2}$ University of Chinese Academy of Sciences, Beijing 100049, China.

${ }^{3}$ State Key Laboratory of Crop Stress Biology for Arid Areas, College of Agronomy, Northwest A\&F University, Yangling 712100, China.

\section{References}

1. Raghothama K. Phosphate acquisition. Annu Rev Plant Physiol Plant Mol Biol. 1999;50:665-93. https://doi.org/10.1146/annurev.arplant.50.1.665.

2. Schachtman DP, Reid RJ, Ayling SM. Phosphorus uptake by plants: from soil to cell. Plant Physiol. 1998;116(2):447-53. https://doi.org/10.1104/pp.116.2.447.

3. Ma J, He P, Xu X, He W, Liu Y, Yang F, et al. Temporal and spatial changes in soil available phosphorus in China (1990-2012). Field Crop Res. 2016;192:13-20. https://doi.org/10.1016/j.fcr.2016.04.006.

4. Ramaekers L, Remans R, Rao IM, Blair MW, Vanderleyden J. Strategies for improving phosphorus acquisition efficiency of crop plants. Field Crop Res. 2010;117(2-3):169-76. https://doi.org/10.1016/j.fcr.2010.03.001.

5. López-Arredondo DL, Leyva-González MA, González-Morales SI, López-Bucio J, Herrera-Estrella L. Phosphate nutrition: improving low-phosphate tolerance in crops. Annu Rev Plant Biol. 2014(65):23.1-.9. https://doi.org/10.1146/annurev-arplant-050213-035949.

6. Lynch J. Root architecture and plant productivity. Plant Physiol. 1995;109(1):7-13. https://doi.org/10.1104/pp.109.1.7.

7. Sánchez-Calderón L, López-Bucio J, Chacón-López A, Cruz-Ramírez A, Nieto-Jacobo F, Dubrovsky JG, et al. Phosphate starvation induces a determinate developmental program in the roots of Arabidopsis thaliana. Plant Cell Physiol. 2005;46(1):174-84. https://doi.org/10.1093/pcp/pci011.

8. Vejchasarn P, Lynch JP, Brown KM. Genetic variability in phosphorus responses of rice root phenotypes. Rice. 2016;9(1):29. https://doi.org/10.1186/s12284-016-0102-9.

9. Heppell J, Talboys P, Payvandi S, Zygalakis KC, Fliege J, Withers PJ, et al. How changing root system architecture can help tackle a reduction in soil phosphate $(P)$ levels for better plant $P$ acquisition. Plant Cell Environ. 2015;38(1):118-28. https://doi.org/10.1111/pce.12376.

10. da Silva A, Bruno IP, Franzini VI, Marcante NC, Benitiz L, Muraoka T. Phosphorus uptake efficiency, root morphology and architecture in Brazilian wheat cultivars. J Radioanal Nucl Ch. 
2015;307(2):1055-63. https://doi.org/10.1007/s10967-015-4282-3.

11. Chiou TJ, Lin SI. Signaling network in sensing phosphate availability in plants. Annu Rev Plant Biol. 2011;62:185-206. https://doi.org/10.1146/annurev-arplant-042110-103849.

12. Zhang Z, Liao H, Lucas WJ. Molecular mechanisms underlying phosphate sensing, signaling, and adaptation in plants. J Integr Plant Biol. 2014;56(3):192-220. https://doi.org/10.1111/jipb.12163.

13. Bari R, Datt Pant B, Stitt M, Scheible WR. PHO2, microRNA399, and PHR1 define a phosphatesignaling pathway in plants. Plant Physiol. 2006;141(3):988-99. https://doi.org/10.1104/pp.106.079707.

14. Zhou Z, Wang Z, Lv Q, Shi J, Zhong Y, Wu P, et al. SPX proteins regulate Pi homeostasis and signaling in different subcellular level. Plant Signal Behav. 2015;10(9):e1061163. https://doi.org/10.1080/15592324.2015.1061163.

15. Nacry P, Canivenc G, Muller B, Azmi A, Van Onckelen H, Rossignol M, et al. A role for auxin redistribution in the responses of the root system architecture to phosphate starvation in Arabidopsis. Plant Physiol. 2005;138(4):2061-74. https://doi.org/10.1104/pp.105.060061.

16. Nagarajan VK, Smith AP. Ethylene's role in phosphate starvation signaling: more than just a root growth regulator. Plant Cell Physiol. 2012;53(2):277-86. https://doi.org/10.1093/pcp/pcr186.

17. Jiang C, Gao X, Liao L, Harberd NP, Fu X. Phosphate starvation root architecture and anthocyanin accumulation responses are modulated by the gibberellin-DELLA signaling pathway in Arabidopsis. Plant Physiol. 2007;145(4):1460-70. https://doi.org/10.1104/pp.107.103788.

18. Ma Z, Baskin TI, Brown KM, Lynch JP. Regulation of root elongation under phosphorus stress involves changes in ethylene responsiveness. Plant Physiol. 2003;131(3):1381-90. https://doi.org/10.1104/pp.012161.

19. Misson J, Raghothama KG, Jain A, Jouhet J, Block MA, Bligny R, et al. A genome-wide transcriptional analysis using Arabidopsis thaliana Affymetrix gene chips determined plant responses to phosphate deprivation. Proc Natl Acad Sci U S A. 2005;102(33):11934-9. https://doi.org/10.1073/pnas.0505266102.

20. Tawaraya K, Horie R, Saito A, Shinano T, Wagatsuma T, Saito K, et al. Metabolite profiling of shoot extracts, root Extracts, and root exudates of rice plant under phosphorus deficiency. J Plant Nutr. 2013;36(7):1138-59. http://dx.doi.org/10.1080/01904167.2013.780613.

21. Huang CY, Roessner U, Eickmeier I, Genc Y, Callahan DL, Shirley N, et al. Metabolite profiling reveals distinct changes in carbon and nitrogen metabolism in phosphate-deficient barley plants (Hordeum vulgare L.). Plant Cell Physiol. 2008;49(5):691-703. https://doi.org/10.1093/pcp/pcn044.

22. Ganie AH, Ahmad A, Pandey R, Aref IM, Yousuf PY, Ahmad S, et al. Metabolite profiling of low-P tolerant and low-P sensitive maize genotypes under phosphorus starvation and restoration conditions. PloS one. 2015;10(6):e0129520. https://doi.org/10.1371/journal.pone.0129520.

23. Hernández G, Ramírez M, Valdés-López 0 , Tesfaye M, Graham MA, Czechowski T, et al. Phosphorus stress in common bean: root transcript and metabolic responses. Plant Physiol. 2007;144(2):75267. https://doi.org/10.1104/pp.107.096958. 
24. Tawaraya K, Horie R, Shinano T, Wagatsuma T, Saito K, Oikawa A. Metabolite profiling of soybean root exudates under phosphorus deficiency. Soil Sci Plant Nutr. 2014;60(5):679-94. http://dx.doi.org/10.1080/00380768.2014.945390.

25. Wang F, Deng M, Xu J, Zhu X, Mao C. Molecular mechanisms of phosphate transport and signaling in higher plants. Seminars in cell \& developmental biology. 2018;74:114-22. https://doi.org/10.1016/j.semcdb.2017.06.013.

26. Chiou TJ, Aung K, Lin SI, Wu CC, Chiang SF, Su CL. Regulation of phosphate homeostasis by MicroRNA in Arabidopsis. Plant Cell. 2006;18(2):412-21. https://doi.org/10.1105/tpc.105.038943.

27. Manske GGB, Ortiz-Monasterio JI, van Ginkel M, González RM, Fischer RA, Rajaram S, et al. Importance of $\mathrm{P}$ uptake efficiency versus $\mathrm{P}$ utilization for wheat yield in acid and calcareous soils in Mexico. Eur J Agron. 2001;14(4):261-74. https://doi.org/10.1016/S1161-0301(00)00099-X.

28. Li H, Liu J, Li G, Shen J, Bergstrom L, Zhang F. Past, present, and future use of phosphorus in Chinese agriculture and its influence on phosphorus losses. Ambio. 2015;44 Suppl 2:S274-85. https://doi.org/10.1007/s13280-015-0633-0.

29. Conley DJ, Paerl HW, Howarth RW, Boesch DF, Seitzinger SP, Havens KE, et al. Ecology. Controlling eutrophication: nitrogen and phosphorus. Science. 2009;323(5917):1014-5. https://doi.org/10.1126/science.1167755.

30. Zhang W, Wang J, Jun J, Wang ZG, An DG, Zhang XQ, et al. Development of "Kn199" new winter wheat variety and its cultivation in China. Chinese Journal of Eco-Agriculture. 2011;19(5):1215-9.

31. Zhao H, Zhang W, Wang J, Ji J, Wang ZG, Li JM. Analysis of high and stable yield characteristics of "Kn199" winter wheat cultivar. Chinese Journal of Eco-Agriculture. 2011;19(5):1220-8.

32. Rubio V, Linhares F, Solano R, Martín AC, Iglesias J, Leyva A, et al. A conserved MYB transcription factor involved in phosphate starvation signaling both in vascular plants and in unicellular algae. Gene Dev. 2001;15(16):2122-33. http://www.genesdev.org/cgi/doi/10.1101/gad.204401.

33. Abu-Zaitoon YM. Phylogenetic analysis of putative genes involved in the tryptophan-dependent pathway of auxin biosynthesis in rice. Appl Biochem Biotechnol. 2014;172(5):2480-95. https://doi.org/10.1007/s12010-013-0710-4.

34. Zhou JJ, Luo J. The PIN-FORMED auxin efflux carriers in plants. Int J Mol Sci. 2018;19:2759. https://doi.org/10.3390/ijms19092759.

35. Larsen PB. Mechanisms of ethylene biosynthesis and response in plants. In: Guilfoyle T, Hagen G, editors. Plant Hormone Signalling. Essays in Biochemistry. 58. London: Portland Press Ltd; 2015. p. 61-70. https://doi.org/10.1042/bse0580061.

36. Schaller A, Stintzi A. Enzymes in jasmonate biosynthesis - structure, function, regulation. Phytochemistry. 2009;70(13-14):1532-8. https://doi.org/10.1016/j.phytochem.2009.07.032.

37. Colebrook EH, Thomas SG, Phillips AL, Hedden $P$. The role of gibberellin signalling in plant responses to abiotic stress. J Exp Biol. 2014;217(Pt 1):67-75. https://doi.org/10.1242/jeb.089938. 
38. del Pozo JC, Diaz-Trivino S, Cisneros N, Gutierrez C. The balance between cell division and endoreplication depends on E2FC-DPB, transcription factors regulated by the ubiquitin-SCFSKP2A pathway in Arabidopsis. Plant Cell. 2006;18(9):2224-35. https://doi.org/10.1105/tpc.105.039651.

39. Hecht V, Vielle-Calzada JP, Hartog MV, Schmidt EDL, Boutilier K, Grossniklaus U, et al. The Arabidopsis SOMATIC EMBRYOGENESIS RECEPTOR KINASE 1 gene is expressed in developing ovules and embryos and enhances embryogenic competence in culture. Plant Physiol. 2001;127(3):803-16. https://doi.org/10.1104/pp.010324.

40. Han YY, Zhou S, Chen YH, Kong X, Xu Y, Wang W. The involvement of expansins in responses to phosphorus availability in wheat, and its potentials in improving phosphorus efficiency of plants. Plant Physiol Biochem. 2014;78:53-62. http://dx.doi.org/10.1016/j.plaphy.2014.02.016.

41. Teng W, Zhao YY, Zhao XQ, He X, Ma WY, Deng Y, et al. Genome-wide identification, characterization, and expression analysis of PHT1 phosphate transporters in wheat. Front Plant Sci. 2017;8:543. https://doi.org/10.3389/fpls.2017.00543.

42. Zhao DY, Zheng SS, Naeem MK, Niu JQ, Wang N, Li ZJ, et al. Screening wheat genotypes for better performance on reduced phosphorus supply by comparing glasshouse experiments with field trials. Plant Soil. 2018;430(1-2):349-60. https://doi.org/10.1007/s11104-018-3739-x.

43. Long L, Ma X, Ye L, Zeng J, Chen G, Zhang G. Root plasticity and Pi recycling within plants contribute to low-P tolerance in Tibetan wild barley. BMC Plant Biol. 2019;19(1):341. https://doi.org/10.1186/s12870-019-1949-x.

44. Borch K, Bouma TJ, Lynch JP, Brown KM. Ethylene: a regulator of root architectural responses to soil phosphorus availability. Plant Cell Environ. 1999;22(4):425-31. https://doi.org/10.1046/j.13653040.1999.00405.x.

45. Ren Y, Qian Y, Xu Y, Zou C, Liu D, Zhao X, et al. Characterization of QTLs for root traits of wheat grown under different nitrogen and phosphorus supply levels. Front Plant Sci. 2017;8:2096. https://doi.org/10.3389/fpls.2017.02096.

46. Park J, Nguyen KT, Park E, Jeon JS, Choi G. DELLA Proteins and their interacting RING finger proteins repress gibberellin responses by binding to the promoters of a subset of gibberellin-responsive genes in Arabidopsis. Plant Cell. 2013;25(3):927-43. https://doi.org/10.1105/tpc.112.108951.

47. Lan P, Li W, Schmidt W. 'Omics' approaches towards understanding plant phosphorus acquisition and use. In: Plaxton WC, Lambers H, editors. Annual Plant Reviews: John Wiley \& Sons, Ltd; 2015. p. 66-80. https://doi.org/10.1002/9781118958841.ch3.

48. Rubio V, Bustos R, Irigoyen ML, Cardona-López X, Rojas-Triana M, Paz-Ares J. Plant hormones and nutrient signaling. Plant Mol Biol. 2009;69(4):361-73. https://doi.org/10.1007/s11103-008-9380-y.

49. Nolan KE, Kurdyukov S, Rose RJ. Expression of the SOMATIC EMBRYOGENESIS RECEPTOR-LIKE KINASE1 (SERK1) gene is associated with developmental change in the life cycle of the model legume Medicago truncatula. J Exp Bot. 2009;60(6):1759-71. https://doi.org/10.1093/jxb/erp046.

50. Singh A, Khurana P. Ectopic expression of Triticum aestivum SERK genes (TaSERKs) control plant growth and development in Arabidopsis. Sci Rep. 2017;7(1):12368. 
https://www.ncbi.nlm.nih.gov/pmc/articles/PMC5620050/.

51. Luo J, Liu Y, Zhang H, Wang J, Chen Z, Luo L, et al. Metabolic alterations provide insights into Stylosanthes roots responding to phosphorus deficiency. BMC Plant Biol. 2020;20(1):85. https://doi.org/10.1186/s12870-020-2283-z.

52. Guo W, Zhao J, Li X, Qin L, Yan X, Liao H. A soybean beta-expansin gene GmEXPB2 intrinsically involved in root system architecture responses to abiotic stresses. Plant J. 2011;66(3):541-52. https://doi.org/10.1111/j.1365-313X.2011.04511.x.

53. Franco-Zorrilla JM, Valli A, Todesco M, Mateos I, Puga MI, Rubio-Somoza I, et al. Target mimicry provides a new mechanism for regulation of microRNA activity. Nat Genet. 2007;39(8):1033-7. https://doi.org/10.1038/ng2079.

54. Huang CY, Shirley N, Genc Y, Shi BJ, Langridge P. Phosphate utilization efficiency correlates with expression of low-affinity phosphate transporters and noncoding RNA, IPS1, in barley. Plant Physiol. 2011;156(3):1217-29. https://doi.org/10.1104/pp.111.178459.

55. Liu N, Shang W, Li C, Jia L, Wang X, Xing G, et al. Evolution of the SPX gene family in plants and its role in the response mechanism to phosphorus stress. Open Biol. 2018;8:170231. http://dx.doi.org/10.1098/rsob.170231.

56. Wang Z, Ruan W, Shi J, Zhang L, Xiang D, Yang C, et al. Rice SPX1 and SPX2 inhibit phosphate starvation responses through interacting with PHR2 in a phosphate-dependent manner. Proc Natl Acad Sci U S A. 2014;111(41):14953-8. https://doi.org/10.1073/pnas.1404680111.

57. Campos PMD, Cornejo P, Rial C, Borie F, Varela RM, Seguel A, et al. Phosphate acquisition efficiency in wheat is related to root:shoot ratio, strigolactone levels, and $\mathrm{PHO} 2$ regulation. J Exp Bot. 2019;70(20):5631-42. https://doi.org/10.1093/jxb/erz349.

58. Neumann G, Römheld V. Root excretion of carboxylic acids and protons in phosphorus-deficient plants. Plant Soil. 1999;211(1):121-30. https://doi.org/10.1023/A:1004380832118.

59. Obata T, Fernie AR. The use of metabolomics to dissect plant responses to abiotic stresses. Cell Mol Life Sci. 2012;69(19):3225-43. https://doi.org/10.1007/s00018-012-1091-5.

60. Araújo WL, Tohge T, Ishizaki K, Leaver CJ, Fernie AR. Protein degradation - an alternative respiratory substrate for stressed plants. Trends Plant Sci. 2011;16(9):489-98. https://doi.org/10.1016/j.tplants.2011.05.008.

61. Ramírez-González RH, Borrill P, Lang D, Harrington SA, Brinton J, Venturini L, et al. The transcriptional landscape of polyploid wheat. Science. 2018;361(6403). https://doi.org/10.1126/science.aar6089.

62. Zheng L, Huang F, Narsai R, Wu J, Giraud E, He F, et al. Physiological and transcriptome analysis of iron and phosphorus interaction in rice seedlings. Plant Physiol. 2009;151(1):262-74. https://doi.org/10.1104/pp.109.141051.

63. Livak KJ, Schmittgen TD. Analysis of relative gene expression data using real-time quantitative PCR and the $2^{-\triangle \Delta C T}$ Method. Methods. 2001;25(4):402-8. https://doi.org/10.1006/meth.2001.1262. 
64. Chong J, Soufan O, Li C, Caraus I, Li S, Bourque G, et al. MetaboAnalyst 4.0: towards more transparent and integrative metabolomics analysis. Nucleic Acids Res. 2018;46(W1):W486-94. https://doi.org/10.1093/nar/gky310.

65. Stacklies W, Redestig H, Scholz M, Walther D, Selbig J. pcaMethods-a bioconductor package providing PCA methods for incomplete data. Bioinformatics. 2007;23(9):1164-7. https://doi.org/10.1093/bioinformatics/btm069.

\section{Figures}

a

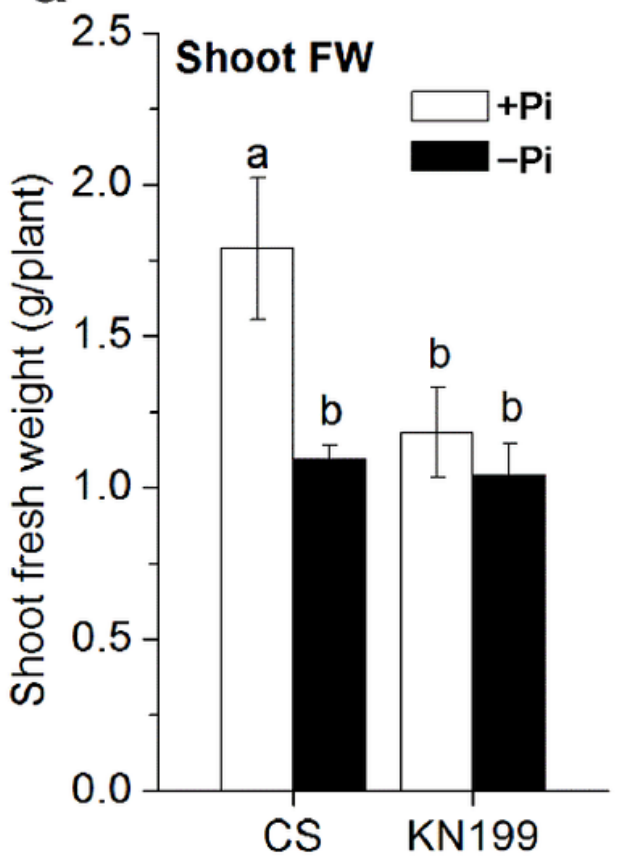

b

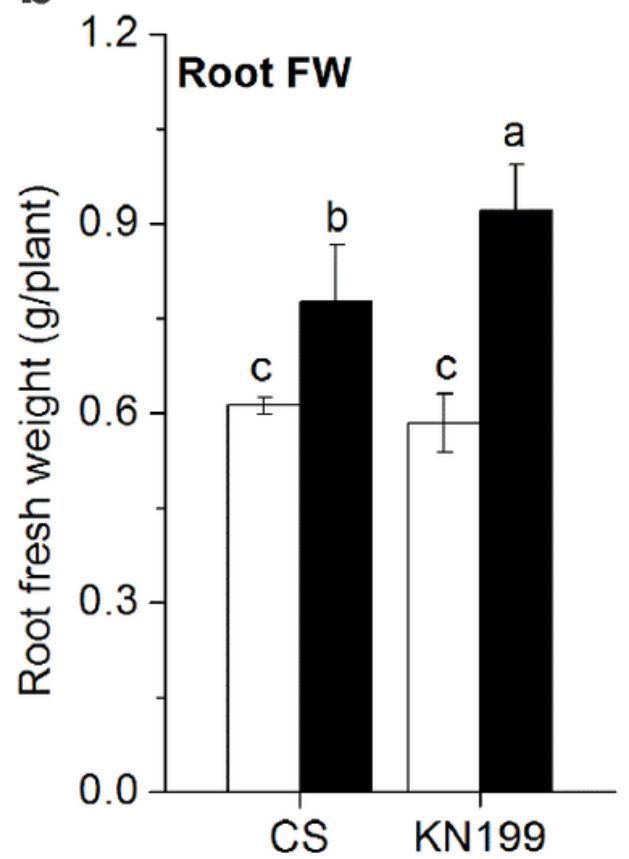

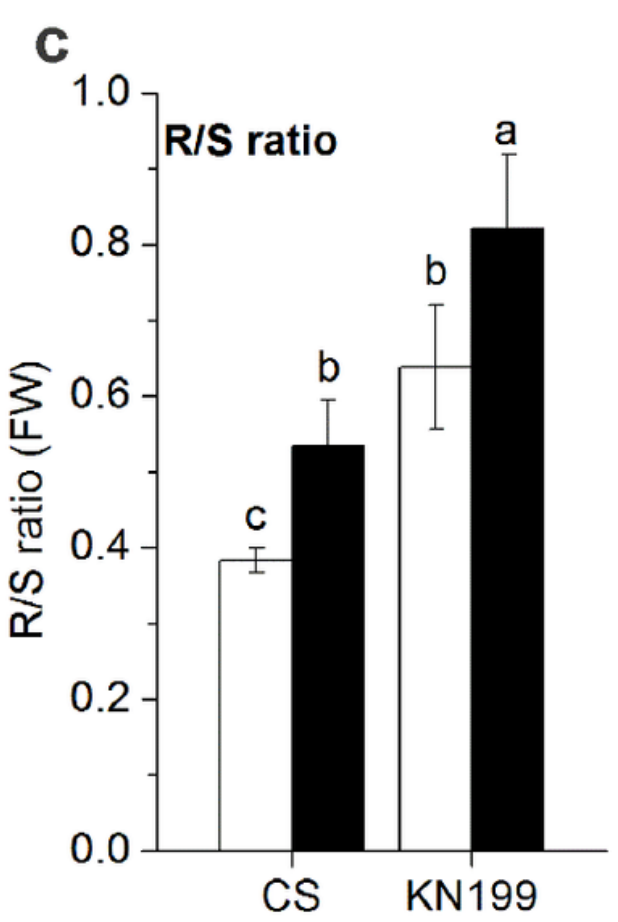

Figure 1

Effect of phosphorus deficiency on the shoot and root of two wheat cultivars. a Shoot fresh weight (FW), $b$ root $\mathrm{FW}$, and $\mathrm{c} \mathrm{R} / \mathrm{S}$ ratio $(\mathrm{FW})$. Twelve-day-old wheat seedlings were grown on sufficient $\mathrm{Pi}(+\mathrm{Pi}$, white bars) or deficient $\mathrm{Pi}(-\mathrm{Pi}$, black bars) solution for seven days. Data are means $\pm \mathrm{SD}(\mathrm{n}=4)$. Different letters indicate significant differences at $p<0.05$ among columns, Duncan's multiple range test. 

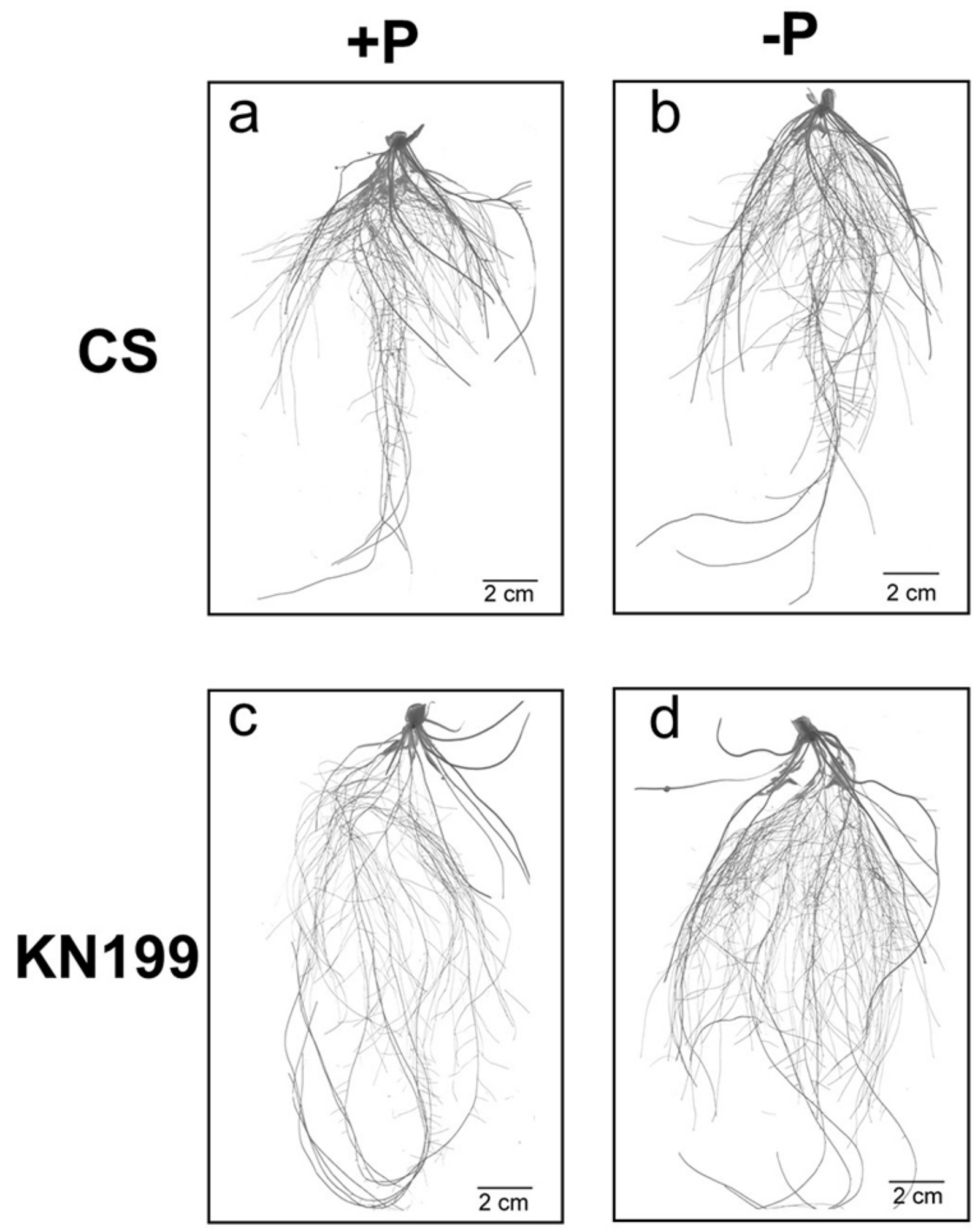

Figure 2

Root morphological performance of the two wheat cultivars. After seven days' treatment on sufficient Pi solution ( $a$ and $c$ ) or deficient Pi solution ( $b$ and $d$ ), photos were taken by the WinRHIZO scanner. 

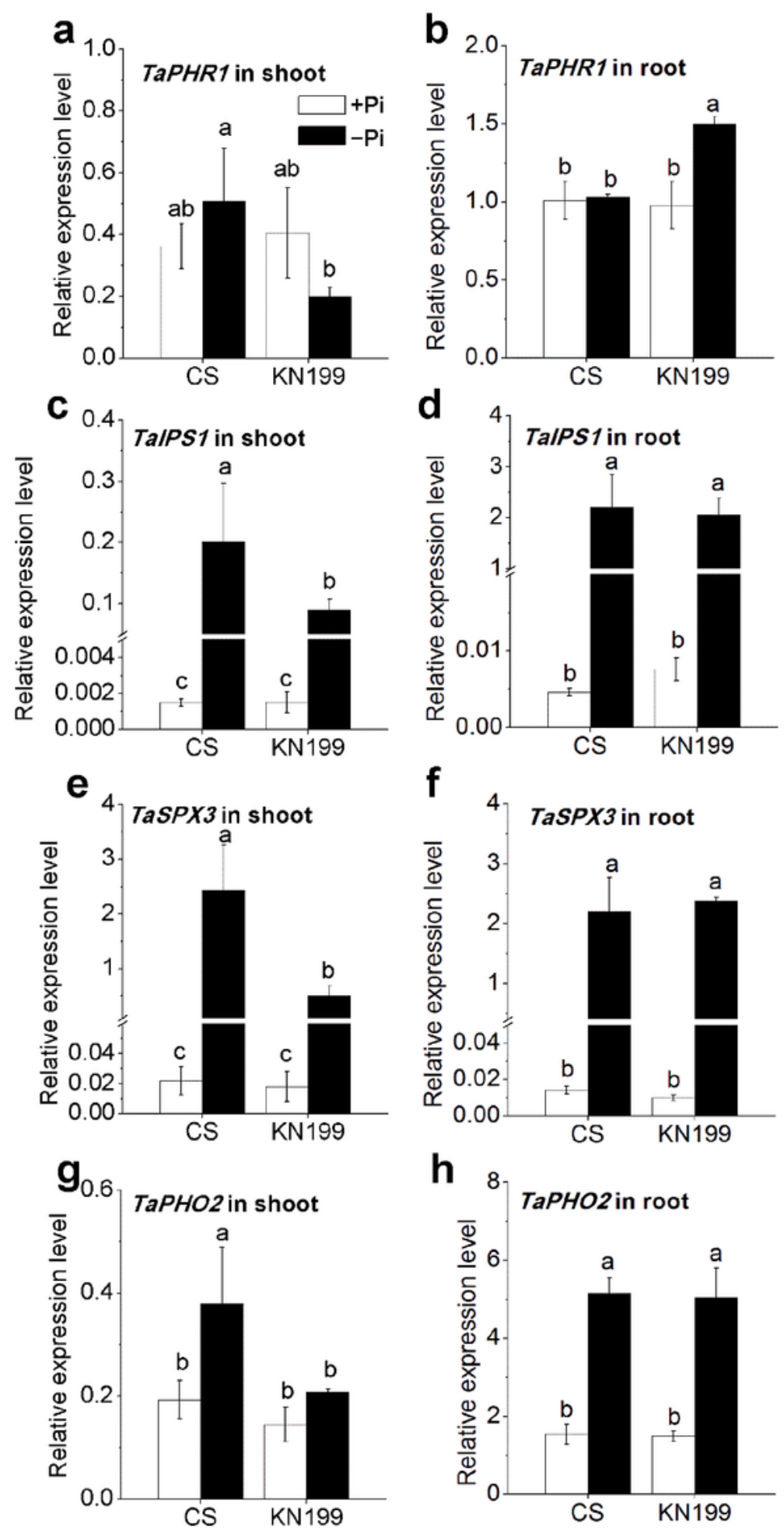

\section{Figure 3}

Gene expression of miR399-mediated Pi signaling related genes in response to Pi deficiency. a-b TaPH1; c-d TaIPS1; e-f TaSPX3; g-h TaPHO2 in the shoots and roots of CS and KN199 after seven days' treatment on sufficient $\mathrm{Pi}(+\mathrm{Pi}$, white bars) or deficient $\mathrm{Pi}(-\mathrm{Pi}$, black bars) solution. The gene expression levels were normalized to the internal control of TaAPT1. The experiments were done using three biological replicates for transcript analysis with three technical replicates for each cDNA sample. Data represent mean values 
$\pm S D(n=4)$. Columns with different letters indicate significant differences $(p<0.05)$ using Duncan's multiple range test
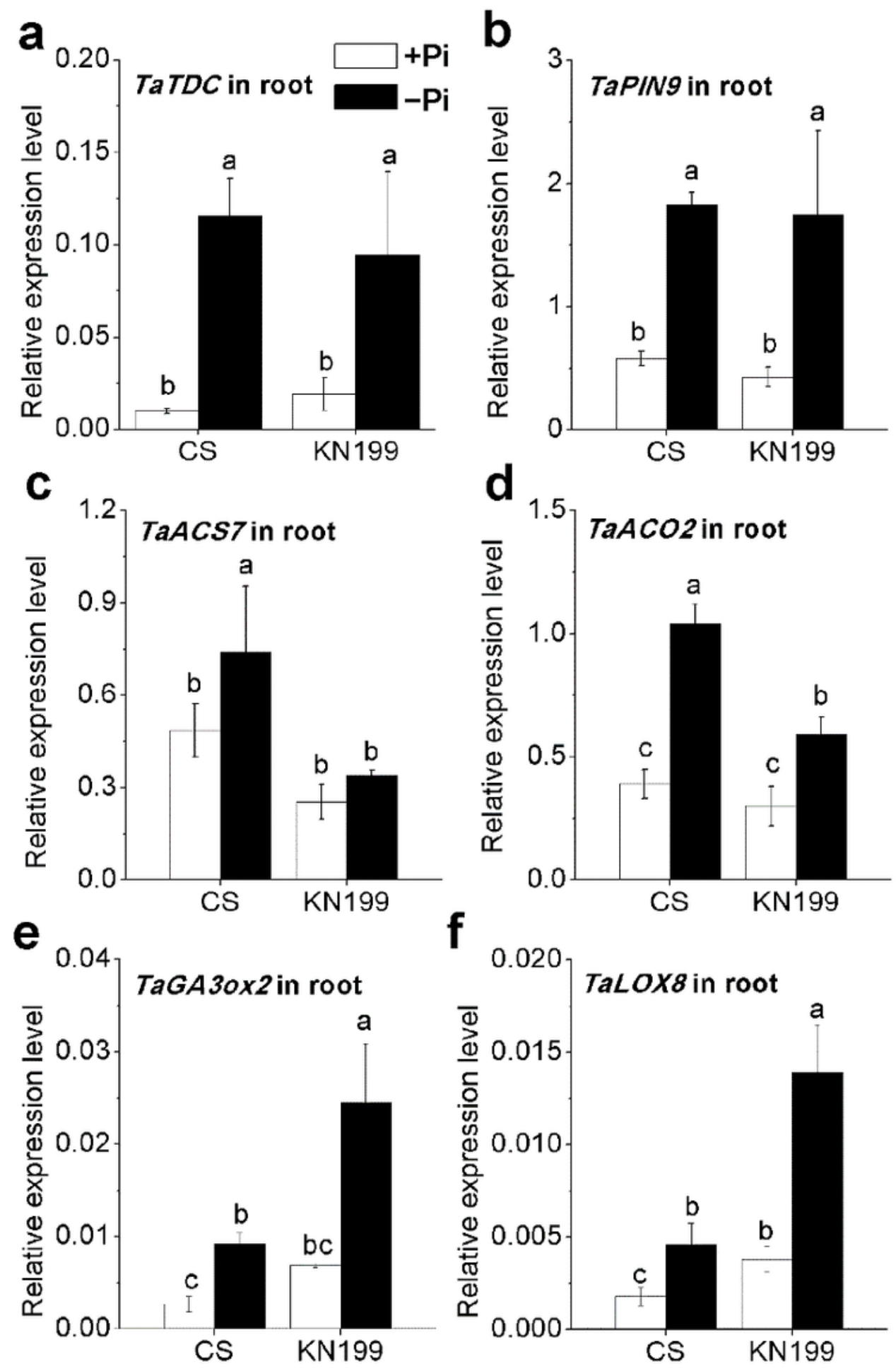

Figure 4

Gene expression of hormone-mediated signaling related genes in response to Pi deficiency. a TaTDC; $b$ TaPIN9; c TaACS7; d TaACO2; e TaGA3ox2; $f$ TaLOX8 in the roots of CS and KN199 after seven days' treatment on sufficient $\mathrm{Pi}(+\mathrm{Pi}$, white bars) or deficient $\mathrm{Pi}(-\mathrm{Pi}$, black bars) solution. Data represent mean 
values $\pm S D(n=4)$, and different letters indicate differences significantly $(p<0.05)$ using Duncan's multiple range test
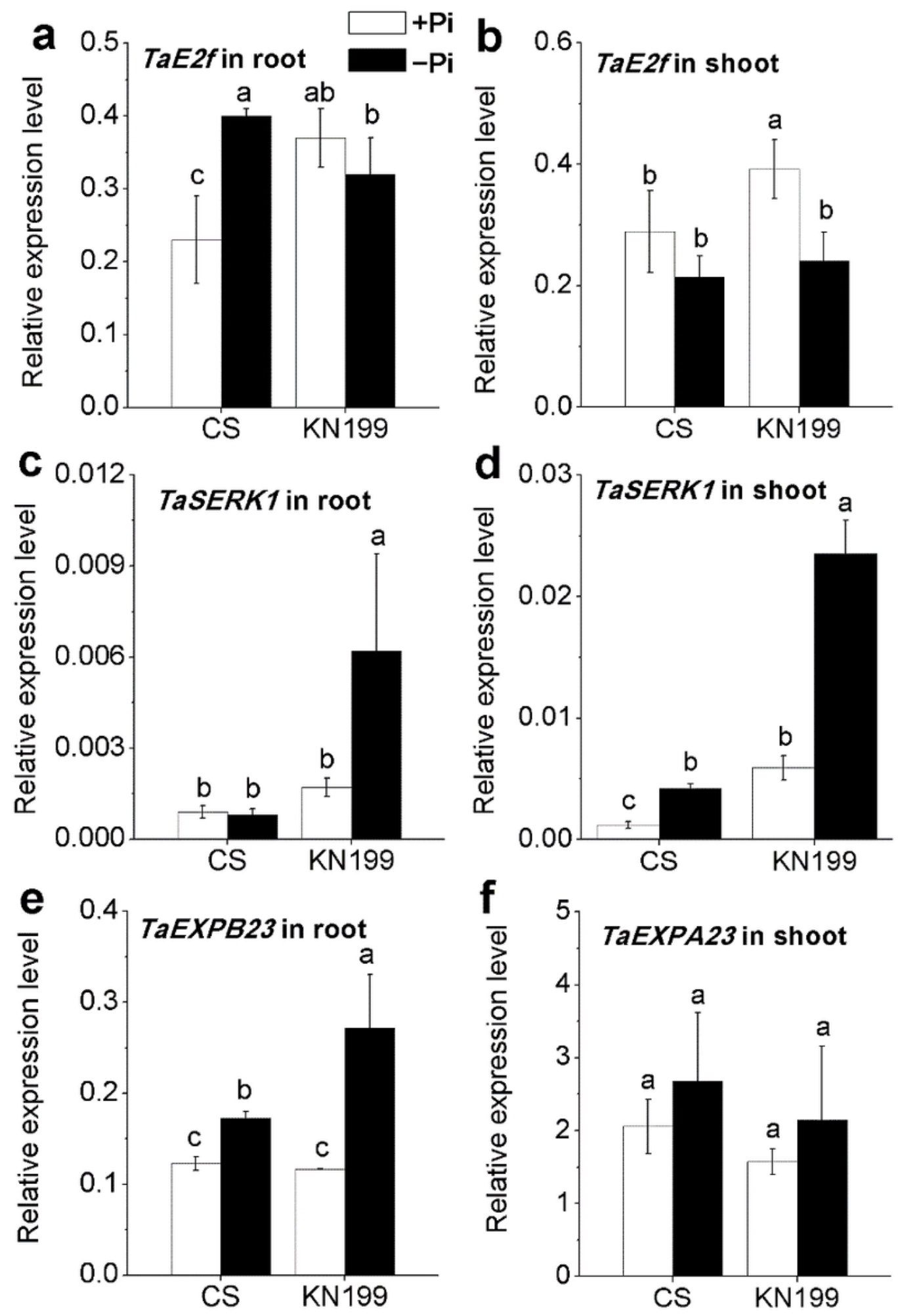

Figure 5

Gene expression of root development related genes in response to Pi deficiency. a-b TaE2f; c-d TaSERK1; e-f TaEXPB23 in the roots and shoots of CS and KN199 after seven days' treatment on sufficient Pi (+Pi, 
white bars) or deficient $\mathrm{Pi}(-\mathrm{Pi}$, black bars) solution. Data represent mean values $\pm \operatorname{SD}(n=4)$, and different letters indicate significant differences $(p<0.05)$ using Duncan's multiple range test.
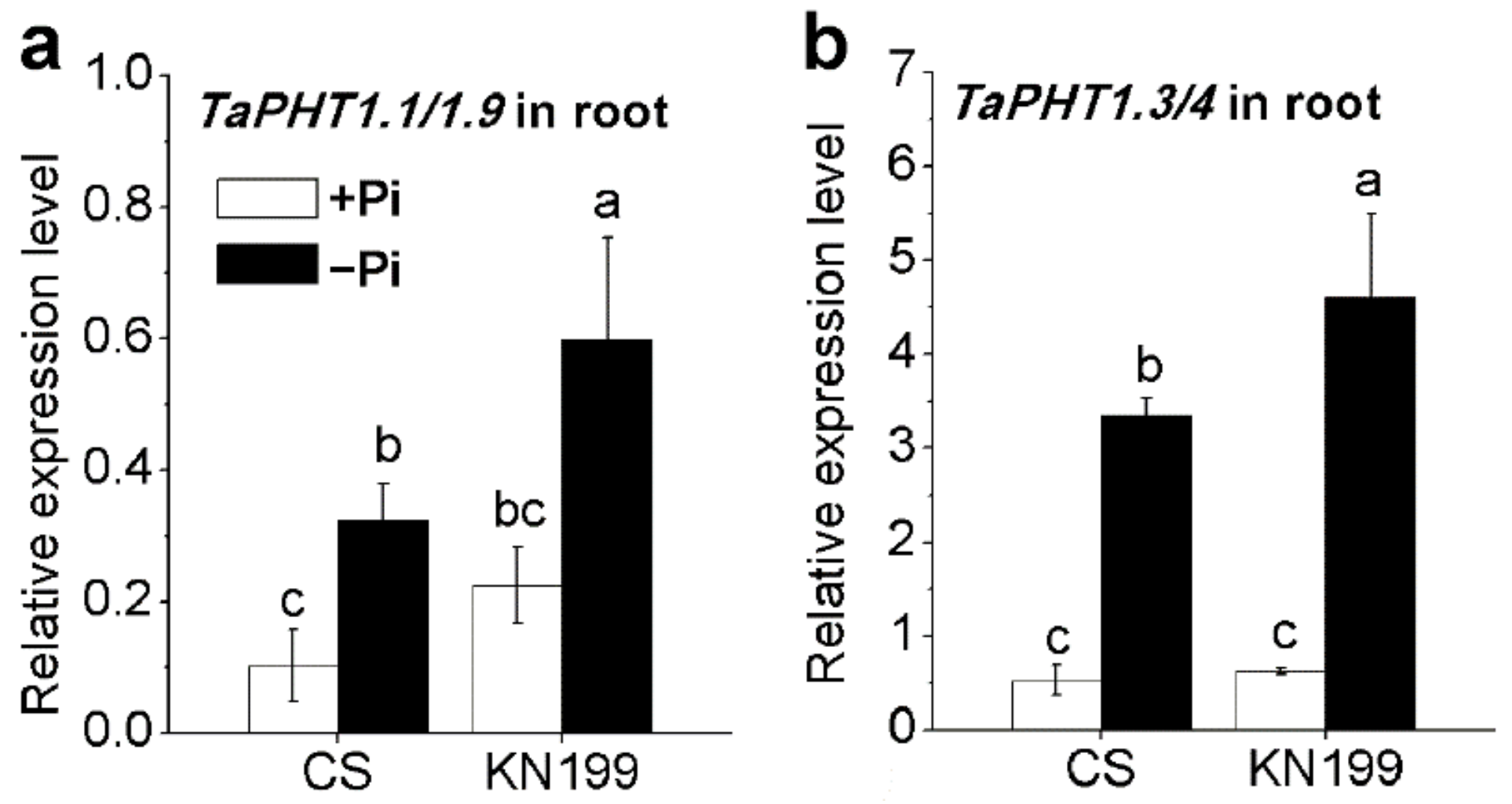

Figure 6

Gene expression of the TaPHT1s genes in response to Pi deficiency. TaPHT1.1/1.9 (a) and TaPHT1.3/4 (b) in the roots of CS and KN199 after seven days' treatment on sufficient Pi (+Pi, white bars) or deficient $\mathrm{Pi}(-\mathrm{Pi}$, black bars) solution. Data represent mean values $\pm \mathrm{SD}(\mathrm{n}=4)$, and different letters indicate significant differences $(p<0.05)$ using Duncan's multiple range test. 


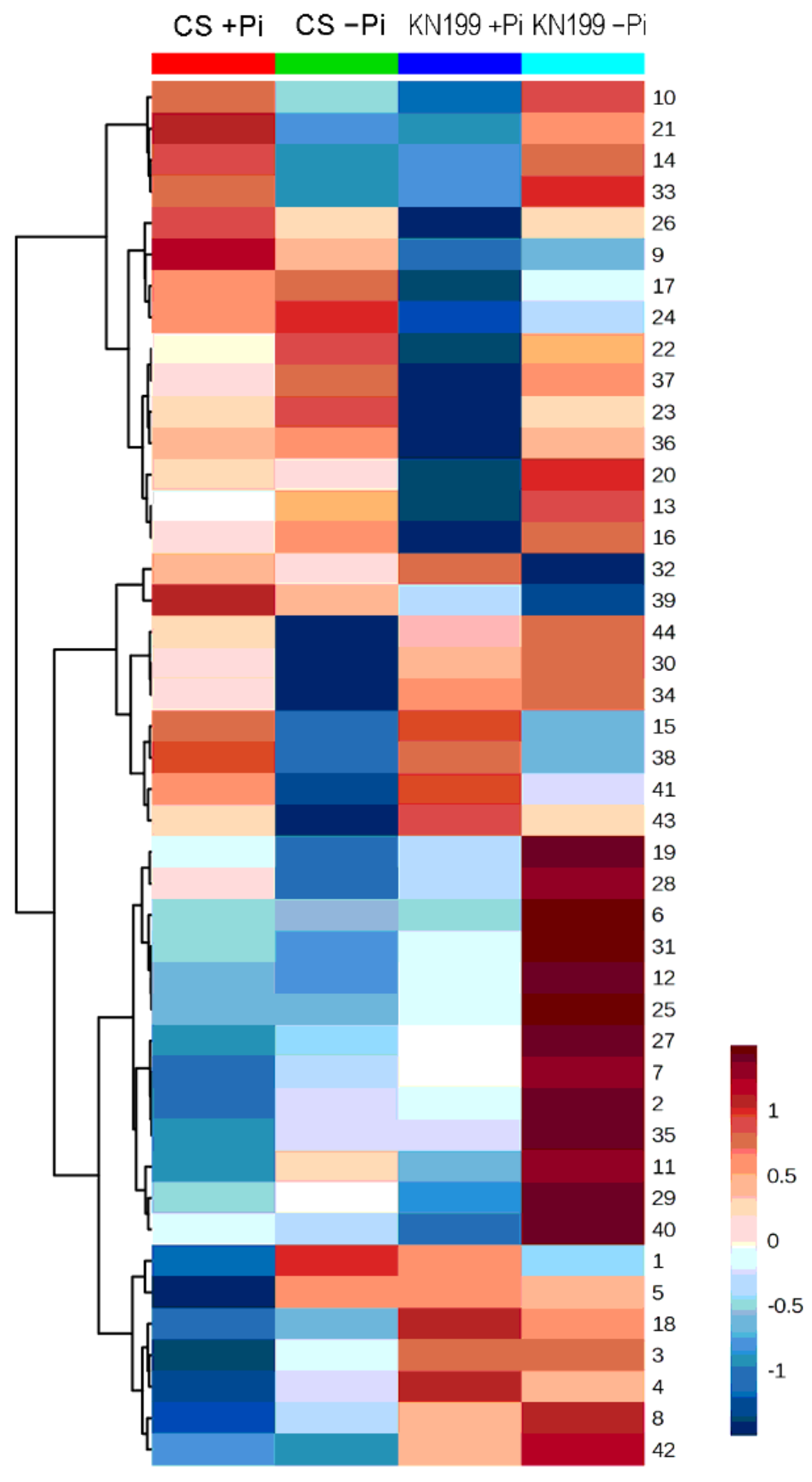

Figure 7

Heatmap and hierarchical cluster analysis for the 44 detected metabolites. The two cultivars, CS and KN199, were detected under sufficient Pi or deficient Pi conditions $(n=4)$. The names of metabolites shown in the corresponding numbers were listed in Additional file 2: Table S1 


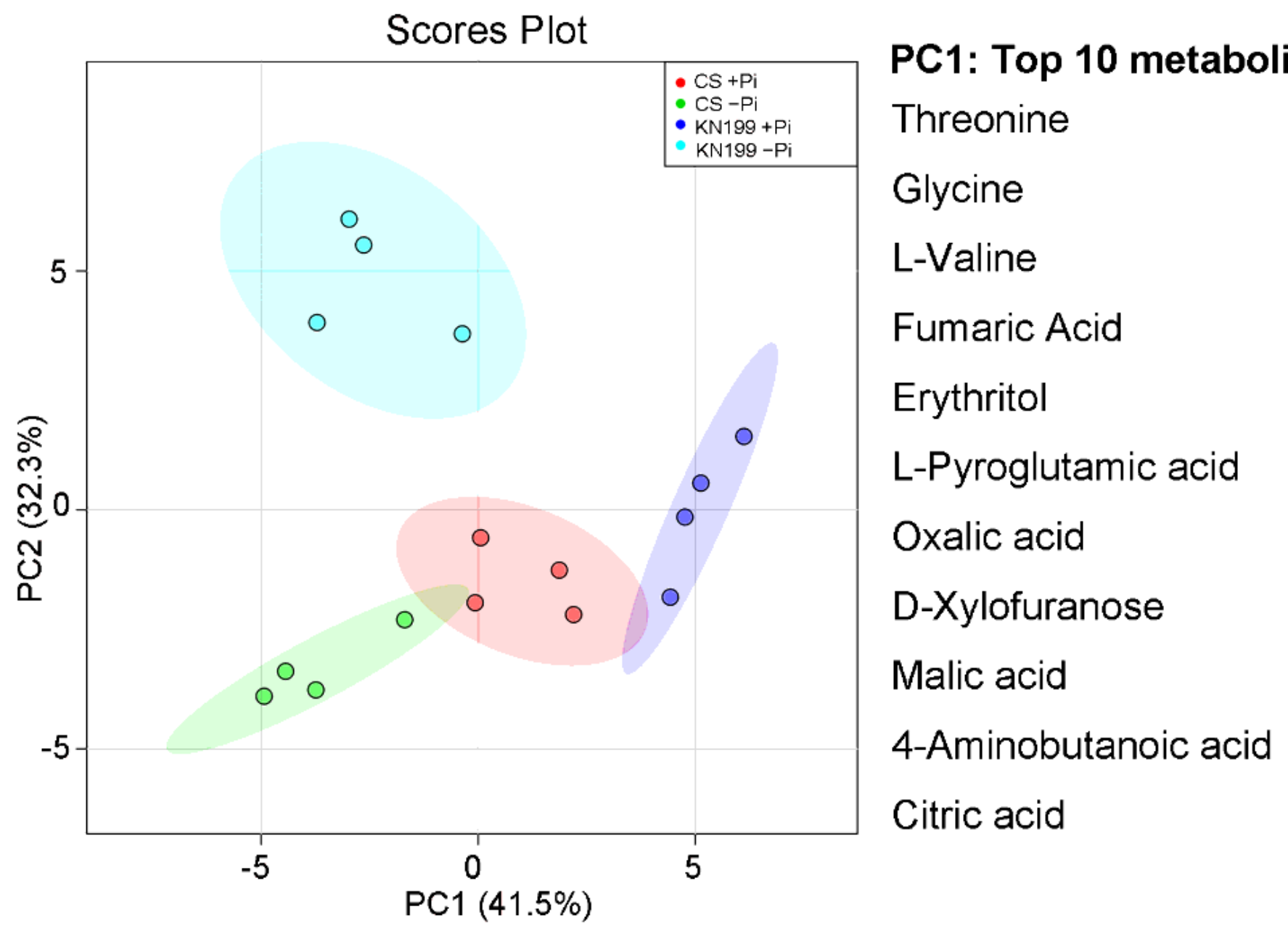

Figure 8

Principle component analysis of root metabolome variation among the two cultivars. The top 10 metabolites contributing to the PC1 are showed. PC1: the first principal component; PC2: the second principal component $(n=4)$. 


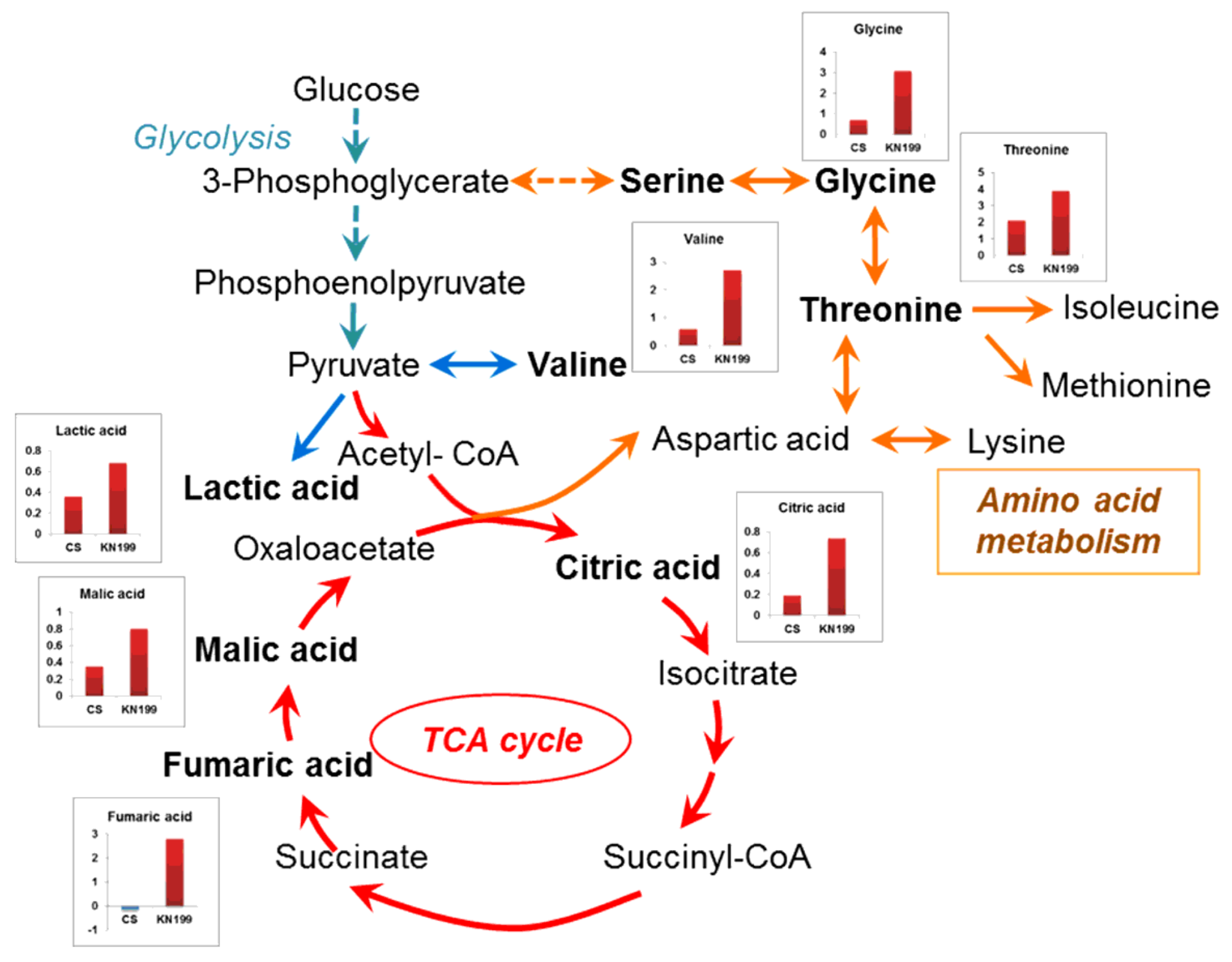

Figure 9

Metabolic pathways of the significantly changed metabolites in response to Pi deficiency. The fold change of the metabolite levels on the $\mathrm{Y}$-axis calculated using formula $\log 2(-\mathrm{Pi} /+\mathrm{Pi})(\mathrm{n}=4)$. Metabolites with red boxes denote significant increases while with blue ones denote significant decreases. The detected metabolites with significant changes in response to Pi deficiency are highlighted in bold.

\section{Supplementary Files}

This is a list of supplementary files associated with this preprint. Click to download.

- Additionalfile1FigureS1.docx

- Additionalfile2TableS1.xIsx

- Additionalfile3TableS2.xlsx 
- Additionalfile4TableS3.xIsx

- Additionalfile5TableS4.xlsx 